\title{
Vertical GaN-on-GaN Schottky Diodes as $\alpha$-Particle Radiation Sensors
}

\author{
Abhinay Sandupatla ${ }^{1, *(\mathbb{D})}$, Subramaniam Arulkumaran ${ }^{2,3}, \mathrm{Ng}$ Geok Ing ${ }^{1,2, *}$, Shugo Nitta ${ }^{3}$, \\ John Kennedy ${ }^{(D)}$ and Hiroshi Amano ${ }^{3}$ (D) \\ 1 School of Electrical and Electronics Engineering, Nanyang Technological University, \\ Singapore 639798, Singapore \\ 2 Temasek Laboratories in Nanyang Technological University, Research Techno Plaza, 50 Nanyang Drive, \\ Singapore 639798, Singapore; Subramaniam@ntu.edu.sg \\ 3 Center for Integrated Research of Future Electronics (CIRFE), IMaSS, Nagoya University, Nagoya 464-8603, \\ Japan; nitta@nagoya-u.jp (S.N.); amano@nuee.nagoya-u.ac.jp (H.A.) \\ 4 National Isotope Center, GNS Science, Lower Hutt 5010, New Zealand; J.Kennedy@gns.cri.nz \\ * Correspondence: abhinay001@e.ntu.edu.sg (A.S.); eging@ntu.edu.sg (N.G.I.)
}

Received: 16 April 2020; Accepted: 8 May 2020; Published: 20 May 2020

\begin{abstract}
Among the different semiconductors, $\mathrm{GaN}$ provides advantages over $\mathrm{Si}, \mathrm{SiC}$ and $\mathrm{GaAs}$ in radiation hardness, resulting in researchers exploring the development of GaN-based radiation sensors to be used in particle physics, astronomic and nuclear science applications. Several reports have demonstrated the usefulness of $\mathrm{GaN}$ as an $\alpha$-particle detector. Work in developing GaN-based radiation sensors are still evolving and $\mathrm{GaN}$ sensors have successfully detected $\alpha$-particles, neutrons, ultraviolet rays, $\mathrm{x}$-rays, electrons and $\gamma$-rays. This review elaborates on the design of a good radiation detector along with the state-of-the-art $\alpha$-particle detectors using GaN. Successful improvement in the growth of GaN drift layers (DL) with 2 order of magnitude lower in charge carrier density (CCD) $\left(7.6 \times 10^{14} / \mathrm{cm}^{3}\right)$ on low threading dislocation density $\left(3.1 \times 10^{6} / \mathrm{cm}^{2}\right)$ hydride vapor phase epitaxy (HVPE) grown free-standing GaN substrate, which helped $\sim 3$ orders of magnitude lower reverse leakage current $\left(I_{R}\right)$ with 3-times increase of reverse breakdown voltages. The highest reverse breakdown voltage of $-2400 \mathrm{~V}$ was also realized from Schottky barrier diodes (SBDs) on a free-standing GaN substrate with $30 \mu \mathrm{m}$ DL. The formation of thick depletion width (DW) with low CCD resulted in improving high-energy $(5.48 \mathrm{MeV}) \alpha$-particle detection with the charge collection efficiency (CCE) of $62 \%$ even at lower bias voltages $(-20 \mathrm{~V})$. The detectors also detected $5.48 \mathrm{MeV}$ $\alpha$-particle with CCE of $100 \%$ from SBDs with $30-\mu \mathrm{m}$ DL at $-750 \mathrm{~V}$.
\end{abstract}

Keywords: GaN-on-GaN; schottky barrier diodes; high-energy $\alpha$-particle detection; low voltage; thick depletion width detectors

\section{Introduction}

Nuclear reactions normally emit different high-energy particles such as $\alpha$-particle, $\beta$-particles, neutrons, $\gamma$-radiation and $x$-rays. As each of these emitted particles interacts with matter differently, a study into $\alpha$-particle detection is highly important [1]. Due to the high mass and density of an $\alpha$-particle, the distance traveled by $\alpha$-particle is limited to only a few centimeters during which it loses all its energy along the path. In general, $\alpha$-particles traverse only a few microns in any solid before losing all its energy. The energy transferred from the $\alpha$-particle gets converted into heat. This distance traversed by $\alpha$-particle plays an important role as only the atoms in this area can interact with the $\alpha$-particle. 


\subsection{Gaseous Ionization Detectors}

Ionization detectors are used to detect ionizing radiation like $\alpha$-particle and $\beta$-particle. Figure 1 shows a typical schematic of an ionization chamber in which an external voltage is applied to keep the conditions in ionization region. A basic ionization detector consists of a chamber filled with a suitable gaseous medium (see Figure 1). Ionization detector is dependent on the effect of a charged particle passing through the gaseous medium. The gaseous medium should have the following qualities:

- chemically stable and inert

- low ionization energy realizes maximum ionization of the medium

- low sensitivity to radiation damage to realize a longer lifetime of the detector.

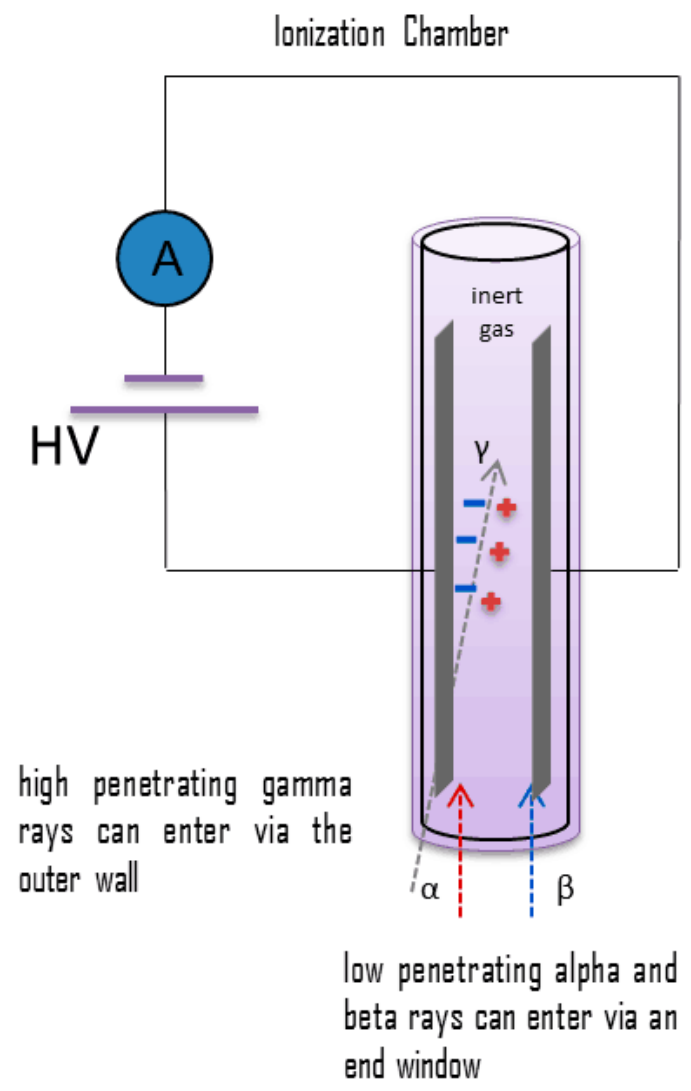

Figure 1. Schematic set-up of an Ionization detector $[2,3]$.

Typically noble gases like helium (He) and argon (Ar) are used in nuclear power plants to measure $\alpha$-particles, $\beta$-particles and $\gamma$-rays.

The ionization chamber has two electrodes across which a very large voltage $(>1 \mathrm{kV})$ is held. When ionizing radiation enters the ionization chamber it generates electron-ion pairs, whose behavior is dependent on the external electric field. Under the high electric field, the generated electron-ion pairs move towards opposite electrodes as the extremely high electric field prevents their recombination.

Ionization chambers are preferred for high radiation dose rates as they do not have any dead time as these detectors have no inherent amplification of the signal. The absence of an amplification component enables the use of ionization chamber immediately after large current detection. In addition, the absence of amplification also helps to provide excellent energy resolution as amplification increases electronic noise.

Although Ionization chambers have many advantages discussed above, the high voltage requirement and the required directionality of incident $\alpha$-particles restricts its use. The use of a gas chamber increases the fragility of the equipment and reduces portability of the detector. Further details on the principle and 
method of operation of ionization detectors can be found in Lamarsh, J.R. et al. [1], Burn, R.R. et al. [4] and Rossi, B. et al. [5].

\subsection{Scintillation Detector}

Scintillation is a flash of light observed when a transparent material interacts with a charged particle. By detecting the flashes of light produced by a scintillator using a photodetector detection of radiation is possible (see Figure 2). A scintillation detector mainly consists of two key elements.

- Scintillator-it generates photons in response to incident radiation.

- Photodetector - a sensitive photodetector converts the incident light into an electrical signal.

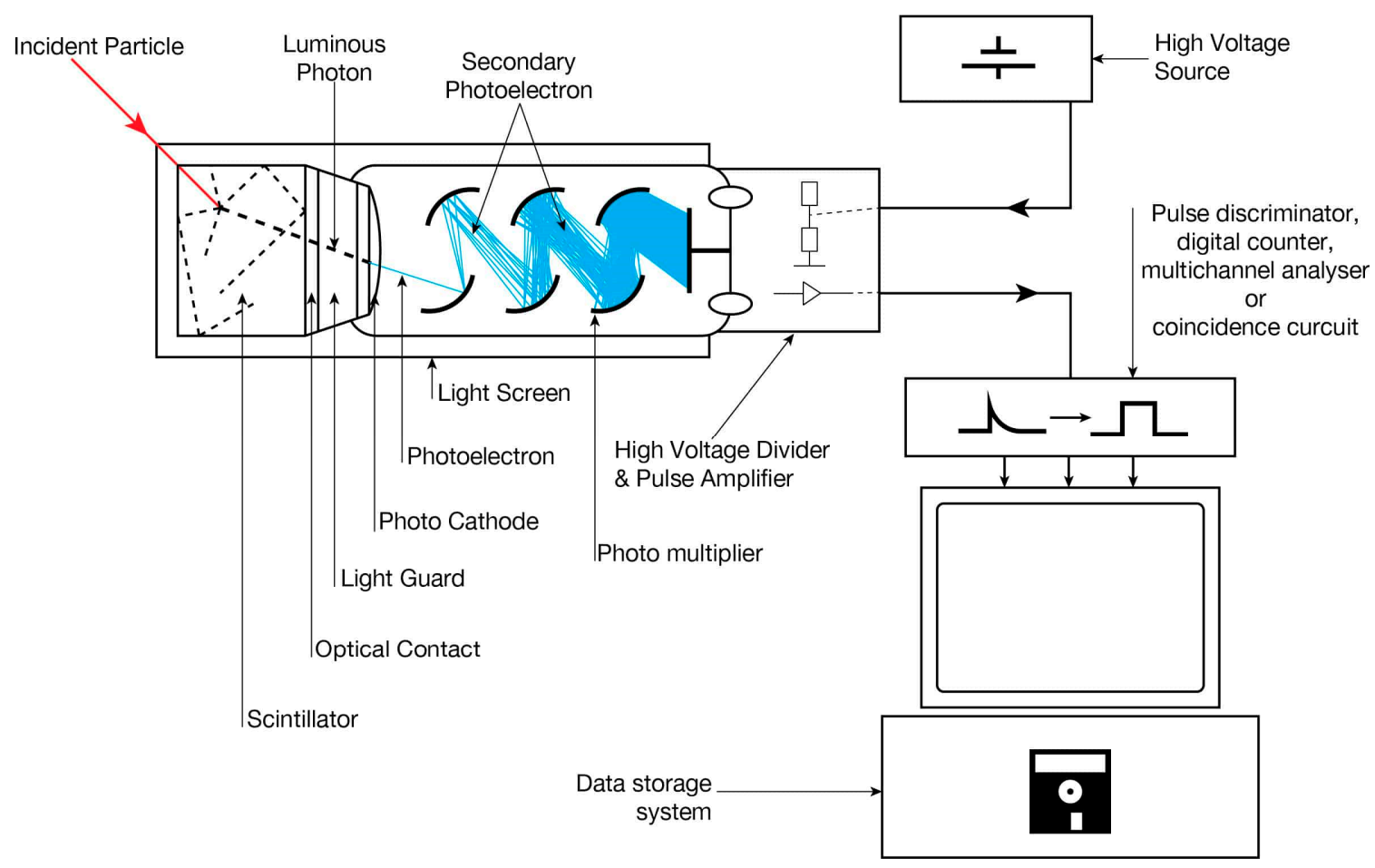

Figure 2. Schematic set-up of a Scintillation detector [3].

The basic operating principle of the scintillation detector involves the conversion of incident radiation energy to optical energy by a scintillator, which produces flashes of varying intensity. The intensity of the optical energy generated is dependent on the energy of the incident radiation (see Figure 2).

Scintillation detectors are highly beneficial for its high efficiency, precision and counting rates.

The intensity of flashes generated by the scintillator and the output voltage is directly proportional to the energy of the incident particle. Therefore scintillators can be used for the determination of the number of incident $\alpha$-particles and their energy.

The use of Scintillation based detector involves multiple energy conversions resulting in conversion losses and introduction of noise. Along with multiple energy conversions presence of amplifiers in the circuit results in a significant dead time which reduces the maximum dosage of $\alpha$-particles which can be detected. The amplifier also introduces electronic noises resulting in poorer energy resolution. Apart from the disadvantages due to the setup, scintillation based detectors generate 1/10 the intensity of light due to the incidence of $\alpha$-particles when compared electrons of the same energy. This reduced sensitivity is due to $\alpha$-particles being heavier in comparison to electrons. Inorganic crystals like ZnS are generally used in the fabrication of scintillators [1,2]. Further details on the principle and method of operation of scintillation detectors can be found in Teo, W.R. et al. [6] and Knoll, G. et al. [7]. 


\subsection{Solid-State Semiconductor Detectors}

Solid-state detectors are made of semiconductors and operate by generating current on interaction with ionizing radiation. The interaction of semiconductor material with ionizing radiation like $\alpha$-particle results in the excitation of an electron. This excited electron moves out of its energy level creating electron-hole (e-h) pairs. The energy of the incident radiation particle is utilized to generate multiple $\mathrm{e}-\mathrm{h}$ pairs, hence higher the incident energy higher the e-h pair generation. Figure 3 shows a schematic of a semi-insulating GaAs $\alpha$-particle detector.

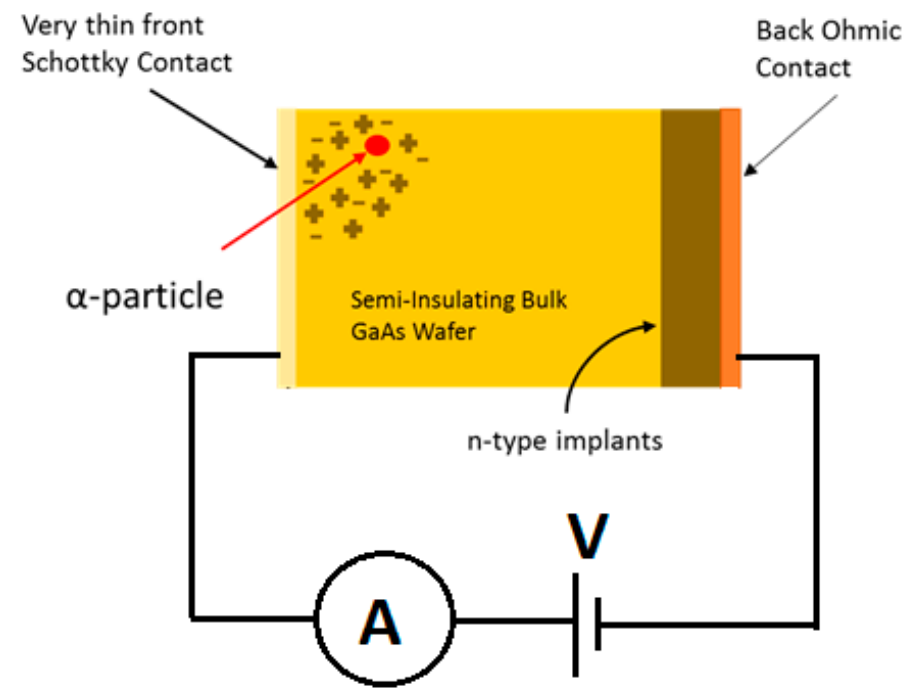

Figure 3. Schematic diagram of GaAs Schottky Barrier Diodes for $\alpha$-particle detection.

Operating principles of Semiconductor radiation detectors:

- $\quad$ Ionizing radiation enters the depletion width (DW) of Schottky Barrier Didoes.

- Radiation passing through the DW generates e-h pairs. The number of e-h pairs generated depends on the incident energy of the particle.

- The external electric field forces e-h pairs to traverse to the electrodes and result in a pulse which can be recorded by an external circuit. The ratio of detected energy to incident energy has been termed as charge collection efficiency (CCE).

- Generated pulse carries information about the energy of the incident radiation and the number of such pulses gives the intensity of the radiation.

Based on the principles of operation of semiconductor detectors, for their successful operation, the following considerations are important. These considerations can be classified into material characteristics and device characteristics.

- Material Characteristics-Material characteristics like the displacement energy $\left(E_{d}\right)$ and e-h pair creation energy of the semiconductor play a vital role. While $E_{d}$ determines the lifetime of the detector, e-h pair creation energy determines the sensitivity of the detector.

- Device characteristics-Electrical characteristics of the fabricated device like the generated DW and leakage current determine the maximum detectable energy incident on the detector and the sensitivity of the detector.

Properties of Selected Semiconductors

While electrical properties like $E_{d}$ and e-h pair creation energy of the semiconductors play a vital role in determining the detector performance, other properties like thermal conductivity, bandgap, breakdown strength and so forth, also play a role. Bandgap defines the lowest detectable energy, 
thermal conductivity regulates the maximum operable temperature range and breakdown strength determines the maximum DW, which can be generated for any material. A summary of important material characteristics has been listed in Table 1 below.

Table 1. Material characteristics of different semiconductors used for the $\alpha$-particle detection along with the best-reported detector performances.

\begin{tabular}{cccccc}
\hline Properties & Si & GaAs & SiC & GaN & Diamond \\
\hline Band gap $(\mathrm{eV})$ & 1.12 & 1.4 & 3.3 & 3.4 & 6 \\
\hline Electron Mobility $\left(\mathrm{cm}^{2} / \mathrm{V} \cdot \mathrm{s}\right)$ & 1450 & 8500 & $800-1000$ & 1000 & $1800-2200$ \\
\hline Sat. elec. Drift velocity $\left(\times 10^{7} \mathrm{~cm} / \mathrm{s}\right)$ & 1.0 & 1.2 & 2 & 2 & 2.7 \\
\hline Breakdown Strength $(\mathrm{MV} / \mathrm{cm})$ & 0.5 & 0.4 & 2.2 & 3.3 & 10 \\
\hline e-h pair creation $(\mathrm{eV})$ & 3.6 & 4.3 & 7.8 & 8.9 & 13 \\
\hline Displacement Energy, $E_{d}(\mathrm{eV})[8]$ & 13 & 10 & $\begin{array}{c}\text { C-20 } \\
\text { Si-35 }[9]\end{array}$ & $\begin{array}{c}\text { G-109 }[10] \\
3\end{array}$ & $35[11]$ \\
\hline Bias Voltage Required to achieve $100 \% \mathrm{CCE}(\mathrm{V})$ & $24[12]$ & $150[13]$ & $200[14]$ & $300[15]$ & $15[16]$ \\
\hline Detected Spectral Energy Resolution $(\%)$ & 0.23 & 15 & 0.25 & 1.29 & 0.35 \\
\hline
\end{tabular}

Si-based radiation detectors-Si has a decently high $E_{d}$ of $13 \mathrm{eV}$ accompanied by a well-developed device fabrication technology [8]. While high $E_{d}$ results in a good life-time of the detector, the established fabrication technology is important to fabricate detectors with wide DW and low leakage currents. Diodes are made from narrow strips of Si $(\sim 100 \mu \mathrm{m})$, which are then reverse biased to generate a thick DW. As $\alpha$-particles pass through this DW, they cause small ionization currents that are detected and measured. Arranging multiple such thin detectors in an array can provide an accurate picture of the $\alpha$-particle distribution in a measurement setup. Such strip detectors are widely used in the Inner Tracking System (ITS) of A Large Ion Collider Experiment (ALICE) [3]. The matured Si technologies have resulted in the development of Si detectors with the lowest energy resolution (0.23\%) [12] which is very advantageous in differentiating various spectra of $\alpha$-particles based on their energies.

Similarly, other semiconductors like GaAs were also explored as an alternative to Si-based detectors. Although $\mathrm{GaAs}$ has lower $E_{d}$ at $10 \mathrm{eV}$ [8], GaAs is a direct energy bandgap semiconductor that allows direct transition of electrons from the valence band to conduction band without any change in their momentum. Electrons in the direct conduction band valley experience very high mobility $\left(\sim 7000 \mathrm{~cm}^{2} / \mathrm{V} \cdot \mathrm{s}\right)$ which helps the device function at lower voltages. The high electron mobility in GaAs accompanied with developed growth process development of GaAs have led to the development of Semi-insulating GaAs based $\alpha$-particle detectors. The low doping density helps generate a thick DW at even at low voltages resulting in decently good energy resolution (0.89\%) [17]. The primary drawback of both GaAs and Si-based detectors is that they have low $E_{d}$ resulting in a lower lifetime of the detector.

Although $\mathrm{SiC}, \mathrm{GaN}$ and Diamond are not as developed in terms of growth and fabrication, their material characteristics exhibit their immense potential as radiation detectors due to their higher $E_{d}$. Among the semiconductors listed in the Table 1, diamond shows the best material characteristics for radiation detection [16], which has resulted in the fabrication of $\alpha$-particle detectors with a high energy resolution of $0.35 \%$ while detecting $5.48 \mathrm{MeV} \alpha$-particles with $100 \%$ CCE at $15 \mathrm{~V}$. Despite the superior material characteristics, the difficulties involved with the growth of a single crystalline diamond accompanied by the cost involved restricts the usage of single crystalline diamond for radiation detection. While SiC based $\alpha$-particle detector have performed exceedingly well in low voltages with good energy resolution $(0.25 \%)$, the $E_{d}$ of $\mathrm{SiC}$ is still lower than $\mathrm{GaN}$ making $\mathrm{GaN}$ a better choice for fabricating $\alpha$-particle detectors. 


\section{GaN $\alpha$-Particle Detector}

Among the III-V semiconductors, Gallium Nitride ( $\mathrm{GaN})$ emerged as the best semiconductor materials for lighting [18-20], electronic [21,22] and sensing applications [23,24] due to their superior inherent material properties such as a high direct bandgap, critical electric field, electron and saturation velocity in comparison with other popular semiconductors. High energy bandgap accompanied with large theoretical $E_{d}(109 \mathrm{eV}$ for $\mathrm{N}$ and $45 \mathrm{eV}$ for Ga) [25] and high thermal stability (melting point $3500 \mathrm{~K}$ at a 9 GPa pressure [26]) has also resulted in GaN being used for radiation detection applications [27]. Compared with semiconductor materials like Si and GaAs, GaN can operate at higher temperatures for a longer time. A review article by Sellin, P.J. in 2006 compared different wide bandgap semiconductors in high radiation environments and concluded that $\mathrm{GaN}$ was a promising candidate for $\alpha$-particle detection despite GaN being relatively immature as a semiconductor [28].

The first group to report an $\alpha$-particle detector fabricated on GaN employed a 2-2.5 $\mu \mathrm{m}$ thick GaN layer grown by metalorganic chemical vapor deposition (MOCVD) on a sapphire substrate. While these detectors performed reasonably well, their performance was highly limited due to the thin DW and high leakage currents in the devices. The absence of free-standing GaN substrate resulted in hetero-epitaxial GaN which used sapphire, $\mathrm{Si}$ or $\mathrm{SiC}$ as its substrates. The high lattice mismatch between epitaxial $\mathrm{GaN}$ with its substrate has resulted in high threading dislocation density (TDD). High TDD increases the reverse leakage current $\left(J_{R}\right)$, which is detrimental to the $\alpha$-particle detector performance.

With the improvement in GaN growth technology researchers developed free-standing GaN with low TDD and thereby GaN-on-GaN wafers. This led to the development of Schottky barrier diodes (SBD) which have thick epitaxial layer and low TDD. Zhao et al. has previously reported the effects of reduced TDD by comparing SBD characteristics of GaN on sapphire and GaN-on-GaN SBDs. Use of GaN substrate has helped reduce TDD by $\sim 3$ orders of magnitude (see Table 2) thereby reduce leakage current by more than $\sim 6$ orders of magnitude [29].

Table 2. Lowest reported threading dislocation density (TDD) in GaN drift layers on different substrates.

\begin{tabular}{ccccc}
\hline Parameter & Si & Sapphire & SiC & GaN \\
\hline Lattice mismatch & $-17 \%$ & $-33 \%$ & $3.5 \%$ & 0 \\
Thermal Mismatch & $116 \%$ & $-23 \%$ & $24 \%$ & 0 \\
TDD $\left(/ \mathrm{cm}^{2}\right)$ & $\sim 10^{9}$ & $\sim 10^{9}$ & $\sim 10^{7}$ & $\sim 10^{4}$ \\
\hline
\end{tabular}

In addition to the semiconductor material properties, the electrical properties of DW also affect the performance of the detector. Devices like p-n diode, pin diode and Schottky diode structures can be used to generate a DW. Detector performance widely depends on the device fabricated.

\section{1. $p$ - $n$ Diodes}

Sugiura, M. et al. has recently reported for the first time a p-n diode-based $\alpha$-particle detector. Figure 4 shows the schematic of $\mathrm{GaN}$ p-n diode used for $\alpha$-particle detection [30]. These $\mathrm{p}$-n diodes exhibited a mobility/life-time product of $4.6 \times 10^{-5} \mathrm{~cm}^{2} / \mathrm{V}$ which is lower than the values reported for CdTe $\left(\sim 10^{-3} \mathrm{~cm}^{2} / \mathrm{V}\right)$ and $\operatorname{TlBr}\left(\sim 10^{-3} \mathrm{~cm}^{2} / \mathrm{V}\right)$. From the values of mobility/life-time product M. Sugiura et al. also concluded that $\mathrm{GaN}$ is a suitable material for radiation sensing applications. 


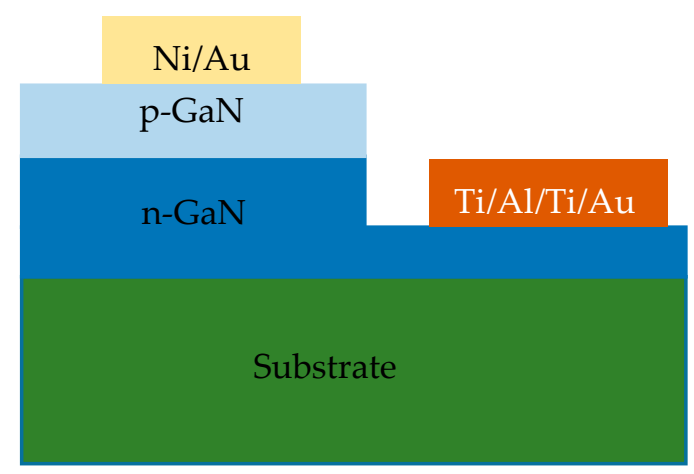

Figure 4. Cross-sectional schematic of GaN p-n diodes for $\alpha$-particle detectors.

\subsection{PIN Diodes}

Wang, G. et al. has reported a PIN diode based $\alpha$-particle detector. The use of an $8 \mu \mathrm{m}$ intrinsic GaN layer between $\mathrm{p}-\mathrm{GaN}$ and $\mathrm{n}-\mathrm{GaN}$ increases the thickness of formed DW, which in turn helps to detect higher energy particles with improved sensitivities [31].

Figure 5 shows the diode schematic of the PIN $\alpha$-particle detector used to detect $700 \mathrm{keV} \alpha$-particles with a CCE of $80 \%$ and an energy resolution of $50 \%$.

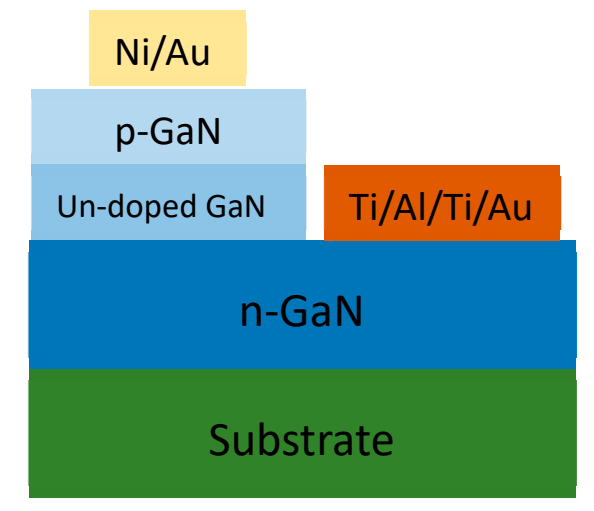

Figure 5. Cross-sectional schematic of GaN PIN diode structure for $\alpha$-particle detector.

Authors also predict the use of a thicker intrinsic layer may increase detectable energy and reduce energy resolution.

\subsection{Schottky Barrier Diodes}

Unlike the $\mathrm{p}-\mathrm{n}$ diodes and PIN diodes, SBDs have been the most popular GaN device for radiation detection. Multiple research groups have fabricated different structures at different stages of the development of GaN growth technologies. The various schematics of different structures of GaN SBD based $\alpha$-particle detectors have been reviewed by Wang, J. et al. [32].

The best performing $\alpha$-particle detector structure is shown in Figure 6 . This kind of structure is called a sandwich structure. The use of a thick GaN layer sandwiched between both electrodes helps generate a thick DW hence detect higher energies of $\alpha$-particles. This structure was first employed by Lee et al. [33] reported the first implementation of a sandwich structure, in which the GaN layer had unintentional $\mathrm{H} 5$ traps in the top $30 \mu \mathrm{m}$ of the active area. These $\mathrm{H} 5$ traps resulted in reducing the charge carrier density (CCD) resulting in the detection of $5.1 \mathrm{MeV} \alpha$-particle energy with $90 \%$ CCE. The sandwich structure was also fabricated by Mulligan et al. [34] but the detector had a very high $\operatorname{CCD}\left(10^{16} / \mathrm{cm}^{3}\right)$ resulting in the formation of a thin DW and detection of only $325 \mathrm{keV} \alpha$-particles. Most recently, $\mathrm{Xu}, \mathrm{Q}$. et al. has reported $\alpha$-particle detector based on a sandwich structure that can detect $5.48 \mathrm{MeV} \alpha$-particles with $100 \%$ CCE at $-550 \mathrm{~V}$ [35], which is the highest detected $\alpha$-particle energy. 


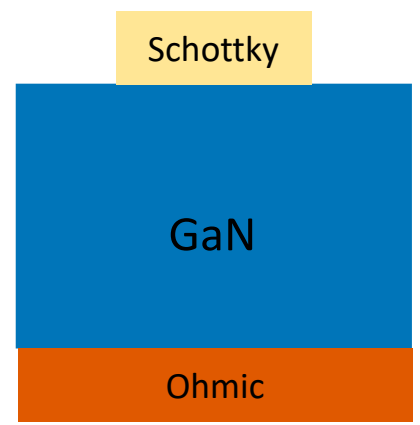

Figure 6. Sandwich structure of alpha particle detectors.

In comparison to the thin film structures, sandwich structures with free-standing GaN substrates have lower TDD. surface morphology Thicker DW helps to detect higher energy particles. Other than TDD, CCD also plays an important role in the generation of a thick DW. Higher CCD reduces DW, hence it is mandatory to reduce the CCD of the detector to detect higher energies. The use of a bulk GaN substrate with low CCD increases the resistance of the detector thereby increasing the voltage required to function at full potential. Table 3 lists all reported $\mathrm{GaN} \alpha$-particle detectors including their structure, detected energy and CCE.

Table 3. The state-of-the-art GaN-based $\alpha$-particle detectors.

\begin{tabular}{|c|c|c|c|c|c|c|}
\hline Affiliation & $\begin{array}{l}\text { Type of } \\
\text { Detector }\end{array}$ & $\begin{array}{l}\text { DLT } \\
(\mu \mathrm{m})\end{array}$ & $\begin{array}{l}\text { Reverse } \\
\text { Bias (V) }\end{array}$ & $\begin{array}{c}\text { Source Energy } \\
(\mathrm{MeV})\end{array}$ & $\begin{array}{l}\text { Det. Energy } \\
(\mathrm{MeV})\end{array}$ & CCE \\
\hline Vilnius Univ. [36] & DSC & $2-2.5$ & 28 & 5.48 & 0.55 & $92 \%$ \\
\hline Institute of Rare Metals [37] & Mesa & 3 & - & 5.157 & 1.129 & $100 \%$ \\
\hline \multirow{2}{*}{ Univ. of Glasgow [38] } & \multirow{2}{*}{ Mesa } & 2.5 & 16 & 5.48 & 0.477 & $94 \%$ \\
\hline & & 12 & 150 & 5.48 & 1.2 & $53 \%$ \\
\hline Ohio State Univ. [34] & Sandwich & bulk & 20 & 5.48 & 0.325 & $6 \%$ \\
\hline Ohio State Univ. [35] & Sandwich & bulk & 550 & 5.48 & 5.48 & $100 \%$ \\
\hline Chonbuk National Univ. [33] & Sandwich & 30/bulk & 120 & 5.1 & 4.59 & $90 \%$ \\
\hline
\end{tabular}

From Table 3, it can be observed that higher energy has been detected by sandwich structures but they require high reverse voltage bias conditions for successful operation. To overcome the high-voltage requirement of a sandwich structure, a low CCD epitaxial layer on highly doped GaN substrate could be used [15]. The low CCD epitaxial layer helps to operate the detector at lower voltages however, highly doped substrate helps to form a low resistance Ohmic contacts.

\section{Design Considerations and Material Characteristics}

In order to improve the low voltage functionality of a GaN-based $\alpha$-particle detector, an epitaxial layer whose thickness is corresponding to the target detectable $\alpha$-particle is required. The required thickness of DW can be simulated using stopping range of ions in matter (SRIM) [39].

From the simulation results shown in Figure 7, $14.58 \mu \mathrm{m}$ was determined to be the minimum DW required to detect $5.48 \mathrm{MeV} \alpha$-particle energy generated from a ${ }^{241} \mathrm{Am}$ source. In order to generate a $14.58 \mathrm{um}$ DW SBDs with $15 \mu \mathrm{m}$ and $30 \mu \mathrm{m}$ drift layer thickness with very low CCD need to be fabricated.

Material characteristics of the GaN DL like crystalline quality, threading dislocation density (TDD), surface morphology and CCD of GaN DL play an important role in determining the detector performance. Use of thick GaN substrate to grow the $15 \mu \mathrm{m}$ and $30 \mu \mathrm{m} \mathrm{GaN} \mathrm{DL}$ has ensured the high crystalline quality of the DL which was measured by 2 theta-omega scan using XRD. The full-wave half maximum (FWHM) was measured at 108.4 arc.sec and 260.6 arc.sec in 002 and 102 orientations, respectively (see Figure 8a and Table 4). These values of measured FWHM are lower than the maximum reported values of $310 \mathrm{arcsec}(002)$ and $350 \mathrm{arc} . \mathrm{sec}$ (102) [40]. The use of a GaN substrate has also reduced the TDD in DL generated due to lattice mismatch between the substrate and the DL. A TDD of 
$3.6 \times 10^{6} / \mathrm{cm}^{2}$ was measured using multiphoton excitation photoluminescence microscopy (MPPL) [41] which was similar to the TDD of the GaN substrate (see Figure $8 \mathbf{b}$ and Table 4). Polishing of the DL has reduced the rms roughness of the surface of the DL $0.206 \mathrm{~nm}$ (see Figure 8c and Table 4). While to reduce the unintentional n-type CCD and increase DW p-type dopant $(\mathrm{Mg})$ was doped in the drift layer [42,43]. The presence of $\mathrm{Mg}$ and its concentration in the DL was extracted from Secondary Ions Mass Spectroscopy (SIMS) analysis. The reduced CCD of $7.6 \times 10^{14} / \mathrm{cm}^{3}$ was measured from the elemental concentrations and verified Hall measurements (see Figure 8d and Table 4).

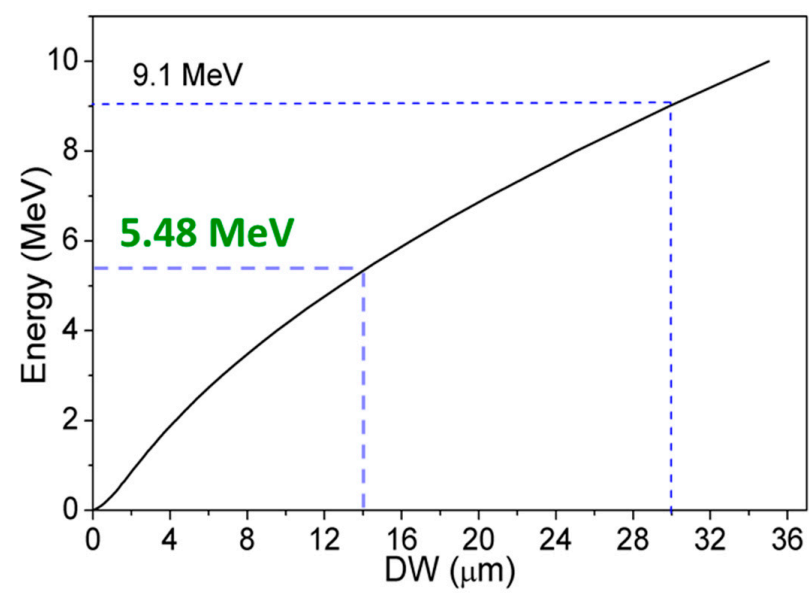

Figure 7. $\alpha$-particle range in GaN calculated by stopping range of ions in matter (SRIM).

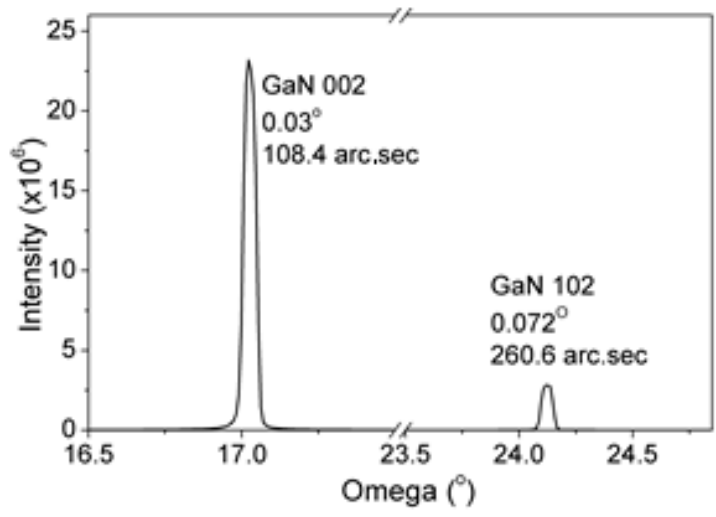

(a)

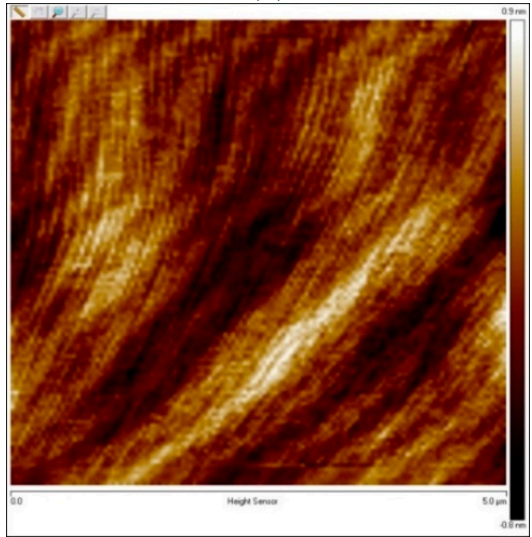

(c)

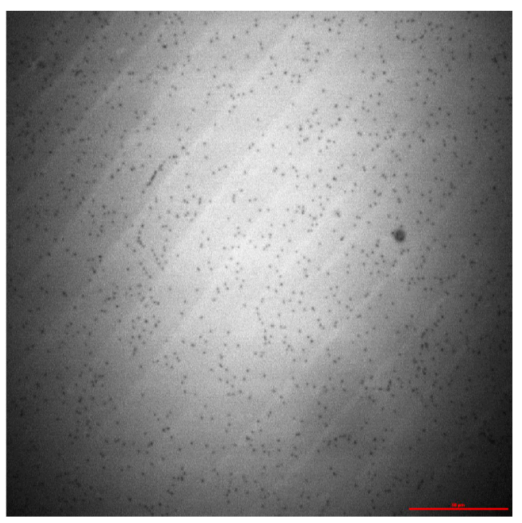

(b)

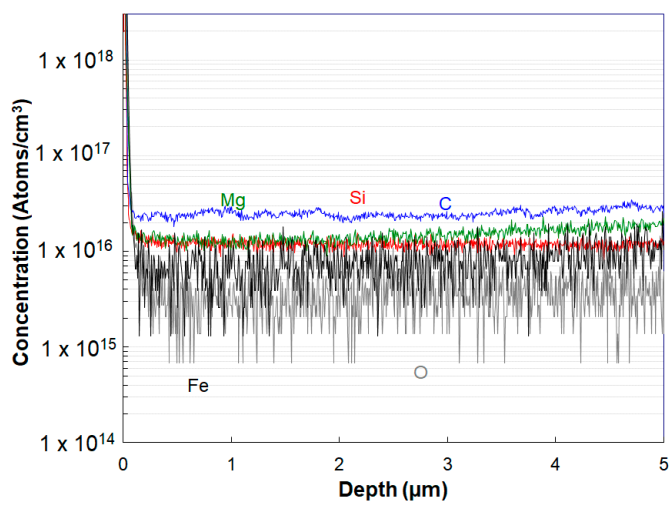

(d)

Figure 8. (a) X-ray diffraction (XRD), (b) TDD (MPPL), (c) Atomic force microscopy (AFM) and (d) SIMS Characteristics of the wafer. 
Table 4. Material properties of MOCVD grown GaN drift layers (DL)s such as 2 theta-omega scan, root mean square (RMS) surface roughness, TDD, elemental concentrations and charge carrier density $(\mathrm{CCD})$ measured by SIMS (Si limit $1.0 \times 10^{14}$ and $\mathrm{Mg}$ limit $2.0 \times 10^{14}$ ) and Hall.

\begin{tabular}{|c|c|c|c|c|c|c|c|c|}
\hline & \multicolumn{2}{|c|}{ XRD (2 theta-omega scan) } & \multirow{2}{*}{$\begin{array}{c}\text { TDD } \\
(\mathrm{MPPL}) \\
\left(\times 10^{6} / \mathrm{cm}^{2}\right)\end{array}$} & \multirow{2}{*}{$\begin{array}{c}\text { RMS } \\
\text { Roughness } \\
(\text { AFM) (nm) }\end{array}$} & \multirow{2}{*}{$\begin{array}{l}\text { Si conc. } \\
\left(/ \mathrm{cm}^{3}\right) \\
\left(\mathrm{N}_{\mathrm{D}}\right)\end{array}$} & \multirow{2}{*}{$\begin{array}{c}\text { Mg conc. } \\
\left(/ \mathrm{cm}^{3}\right) \\
\left(\mathrm{N}_{\mathrm{A}}\right)\end{array}$} & \multicolumn{2}{|c|}{$C C D=N_{D}-N_{A}\left(/ \mathrm{cm}^{3}\right)$} \\
\hline $\begin{array}{l}\text { DLT } \\
(\mu \mathrm{m})\end{array}$ & $\begin{array}{c}002 \\
\text { (arc.sec) }\end{array}$ & $\begin{array}{c}102 \\
\text { (arc.sec) }\end{array}$ & & & & & SIMS & Hall \\
\hline 15 & 108.4 & 260.6 & 3.3 & 0.206 & $1.5 \times 10^{16}$ & $1.5 \times 10^{16}$ & $7.6 \times 10^{14}$ & $7.5 \times 10^{14}$ \\
\hline 30 & 130 & 236 & 4.2 & 0.210 & $6 \times 10^{15}$ & $1 \times 10^{15}$ & $5 \times 10^{15}$ & $5.2 \times 10^{15}$ \\
\hline
\end{tabular}

\section{Detector Fabrication}

The SBD fabrication started with a complete cleaning of the wafer with piranha solution $\left(\mathrm{H}_{2} \mathrm{SO}_{4}: \mathrm{H}_{2} \mathrm{O}_{2}=4: 1\right)$ and organic cleaning (acetone and isopropanol) followed by dipping the wafer in buffered oxide etchant (BOE) for $2 \mathrm{~min}$ for the formation of an excellent metal-semiconductor interface [44]. After the preparation of the surface, the ohmic contact was formed by depositing $\mathrm{Ti} / \mathrm{Al} / \mathrm{Ni} / \mathrm{Au}(20 / 120 / 40 / 50 \mathrm{~nm})$ at the bottom of the wafer (N-face) of the wafer using e-beam, followed by rapid thermal annealing at $775^{\circ} \mathrm{C}$ for $30 \mathrm{~s}$ in $\mathrm{N}_{2}$ ambience. Ti acts as the first layer of Ohmic stack which forms a low-resistance contact, as Ti helps in the generation of $\mathrm{N}$-vacancies after annealing, which increases CCD and promotes tunneling [45]. The second layer deposited was Al which is used to absorb excessive Ti material [44], while $\mathrm{Ni}$ is used as a barrier metal, which confines the downward diffusion of the fourth layer $(\mathrm{Au})$ [46]. The top layer of Au protects layers below from oxidization [47]. Multiple SBDs of varying sizes were then fabricated by depositing Ni/Au (50/1000 nm) on the Ga-face of the wafer. Ni was selected to be the first layer due to the difference in work functions of $\mathrm{GaN}(4.2 \mathrm{eV})$ and $\mathrm{Ni}(5.04 \mathrm{eV})$ [48], which helps to form good Schottky contact (see Figure 9).

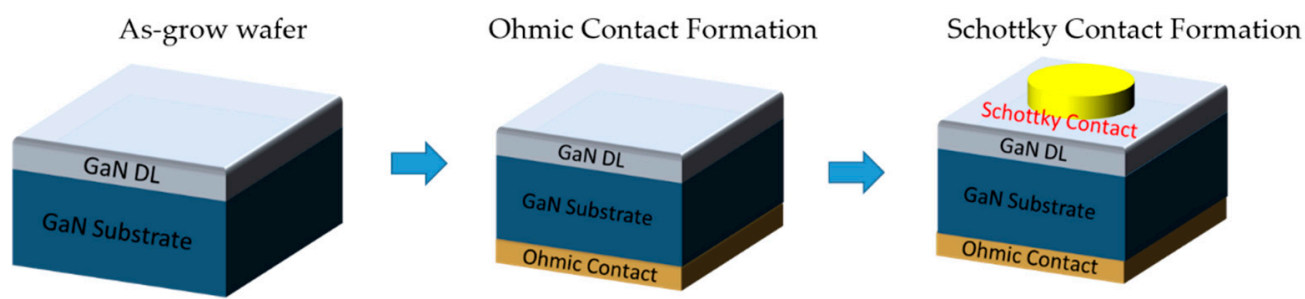

Figure 9. Fabrication of $1 \mathrm{~mm} \mathrm{GaN} \mathrm{Schottky} \mathrm{barrier} \mathrm{diodes} \mathrm{(SBD).}$

\section{Electrical Characterization of SBD}

To understand the effects of Mg-compensation on the performance of the SBDs, the electrical characteristics of an Mg-compensated SBDs with 2 different DL thicknesses (15 $\mu \mathrm{m}$ and $30 \mu \mathrm{m})$.

\subsection{I-V Characterization}

Figure 10a and b show both the reverse and forward current characteristics of SBDs with $15 \mu \mathrm{m}$ and $30 \mu \mathrm{m}$. It can be observed in Figure 10a that both SBDs exhibit similar $I_{R}$ at $-20 \mathrm{~V}$. Figure 10b shows the forward characteristics in which we observe a slight decrease in forward saturation current $\left(I_{s a t}\right)$, the drop observed could be due to increase in DL thickness. Increased series resistance due to an increase in DL is the primary cause of the decrease in $I_{\text {sat }}$.

From the measured forward I-V characteristics, Ideality Factor (n) and Barrier Height $\left(\Phi_{B}\right)$ were extracted using Equations (1) and (2) [2].

$$
\begin{gathered}
\Phi_{B}=K T q \ln I_{\text {sat }} A A * T^{2} \\
I=(e q V n K T /-1),
\end{gathered}
$$


where $I_{\text {sat }}$ is the forward saturation current, $A$ is the SBD contact area, $\mathrm{K}$ is the Boltzmann's constant and $\mathrm{A}^{*}$ is the Richardson's constant with a theoretical value of $26.9 \mathrm{~A} / \mathrm{cm}^{2} \cdot \mathrm{K}^{2}$.
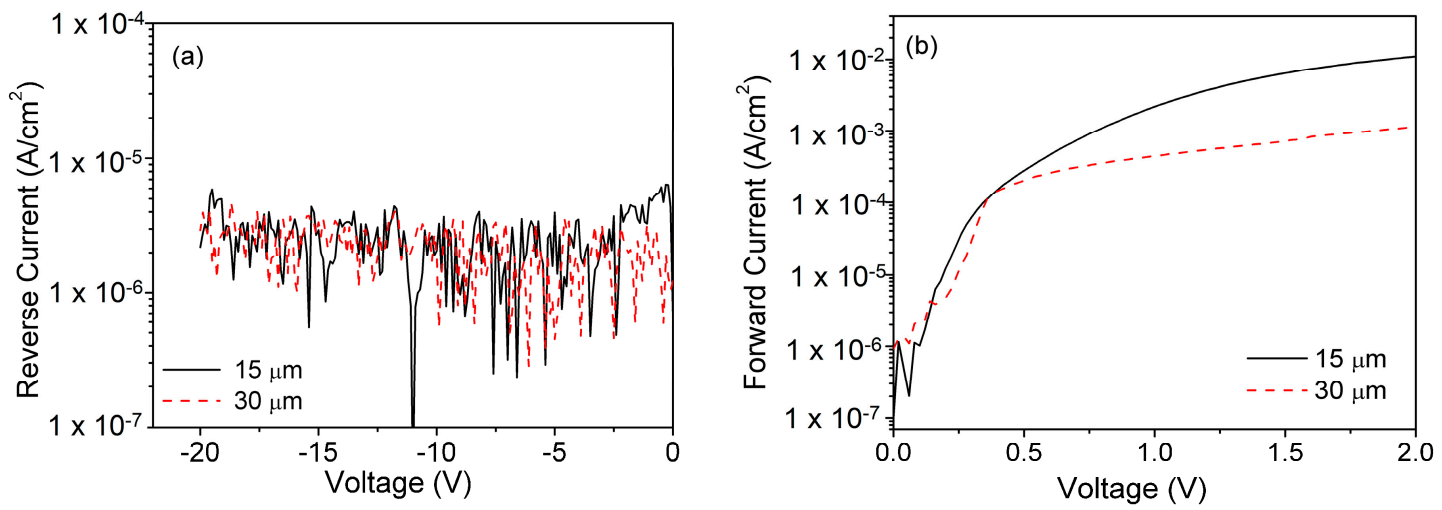

Figure 10. (a) Reverse and (b) Forward $I-V$ characteristics of SBDs with $15 \mu \mathrm{m}$ and $30 \mu \mathrm{m}$ GaN DL.

Average ideality factors of 1.03 and 1.05 were extracted from 10 SBDs with compensated and conventional DL, respectively. The near-unity ideality factor signifies an excellent metal-semiconductor interface at the Schottky-semiconductor contact. The use of the Piranha solution followed by organic cleaning and dipping in BOE for 2 min has resulted in the formation of an excellent metal-semiconductor interface. The similarity of values in $n$ among the SBDs with both $15 \mu \mathrm{m}$ and $30 \mu \mathrm{m}$ DLs indicates the thickness of DLs does not play any role in the determination of $\mathrm{n}$ [49]. Similarly, the extracted $\Phi_{B}$ for both SBDs of $0.81 \mathrm{eV}(15 \mu \mathrm{m})$ and $0.78 \mathrm{eV}(30 \mu \mathrm{m})$ SBDs are close to each other and similar to other reported $\Phi_{B}$ for Ni-based Schottky contacts (see Table 5). From the comparison, the extracted $\mathrm{n}$ and $\Phi_{B}$ were found to be within the reported range of 1.01 to 1.4 for the ideality factor and $0.74 \mathrm{eV}$ to $1.1 \mathrm{eV}$ for barrier height.

Table 5. List of state-of-the-art SBDs fabricated on GaN-on-GaN wafers.

\begin{tabular}{ccccc}
\hline Affiliation & DL $(\mu \mathrm{m})$ & $\mathbf{C C D}\left(\mathbf{c m}^{3}\right)$ & Barrier Height $(\mathbf{e V})$ & Ideality Factor \\
\hline NTU [49] & 15 & $7.6 \times 10^{14}$ & 0.81 & 1.03 \\
\cline { 2 - 5 } & 30 & $3 \times 10^{15}$ & 0.78 & 1.3 \\
\hline Army Res. Labs & 6.6 & $3 \times 10^{16}$ & 0.75 & 1.05 \\
\cline { 2 - 5 } Maryland [50,51] & 2 & $2 \times 10^{16}$ & 0.79 & 1.1 \\
\hline AIST Japan [52] & - & $5 \times 10^{16}$ & 0.74 & 1.09 \\
\hline Toyoda Gosei Co. [53] & 10 & $2.2 \times 10^{16}$ & 1.01 & 1.01 \\
\hline University of Fukui [54] & 12 & $10^{16}$ & 1.05 & 1.4 \\
\hline Univ. of Notre Dame [29] & 0.3 & $3 \times 10^{16}$ & 1.1 & \\
\hline
\end{tabular}

\subsection{Capacitance-Voltage $(C-V)$ Characteristics}

$\mathrm{C}-\mathrm{V}$ measurements were performed to extract the DW of the SBDs. No significant variation in capacitance was observed in a voltage range of $-20 \mathrm{~V}$ to $5 \mathrm{~V}$ (see Figure 11), which signifies the complete depletion of the DL $[55,56]$. 


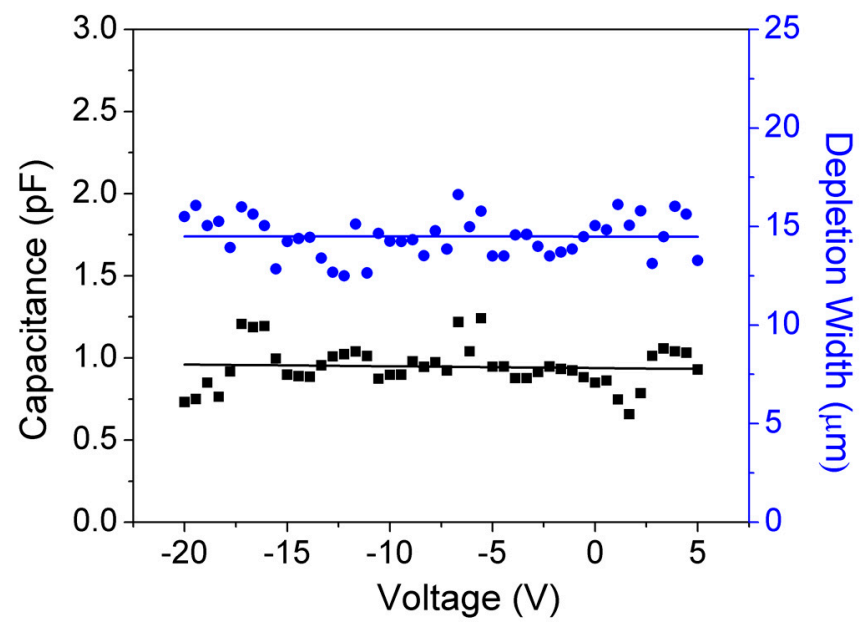

Figure 11. Variation of capacitance and DW with voltage of $0.5 \mathrm{~mm}$ diameter GaN SBDs with $15 \mu \mathrm{m}$.

DW can be extracted from the C-V characteristics using Equation (3):

$$
C=\varepsilon_{0} \varepsilon_{r}(A / D W)
$$

A uniform DW of $\sim 15 \mu \mathrm{m}$ was measured at all voltages ( $-20 \mathrm{~V}$ to $5 \mathrm{~V})$, which implies the total depletion of DL even at $0 \mathrm{~V}$.

\subsection{Reverse Conduction Mechanism of SBD}

Reverse Conduction mechanism (CM) helps to understand the physical constituents leading to the reverse leakage current $\left(J_{R}\right)$ Thermionic Emission (TE) is present if all electrons traverse over the barrier and Thermionic Field Emission (TFE) is the dominant CM if electrons tunneling through the barrier. The study of CM at elevated temperatures is worthy and important to understand the overall performance of the fabricated SBDs. Moreover, high voltages are required to generate a thick DW which will help in the detection of higher energies with improved sensitivity and higher CCE $[15,35]$. CM of $J_{R}$ was extracted by comparing measured $J_{R}$ with theoretically calculated $J_{R}$ using equations for TE and TFE. Further details on the extraction of CM have been reported [43,57]. Figure 12 shows the measured $J_{R}$ at different temperatures over a wide voltage range for SBDs with (a) $15 \mu \mathrm{m}$ DL and (b) $30 \mu \mathrm{m}$ DL. I-V-T characteristics of both devices have been divided into 3 zones depending on the observed CM.
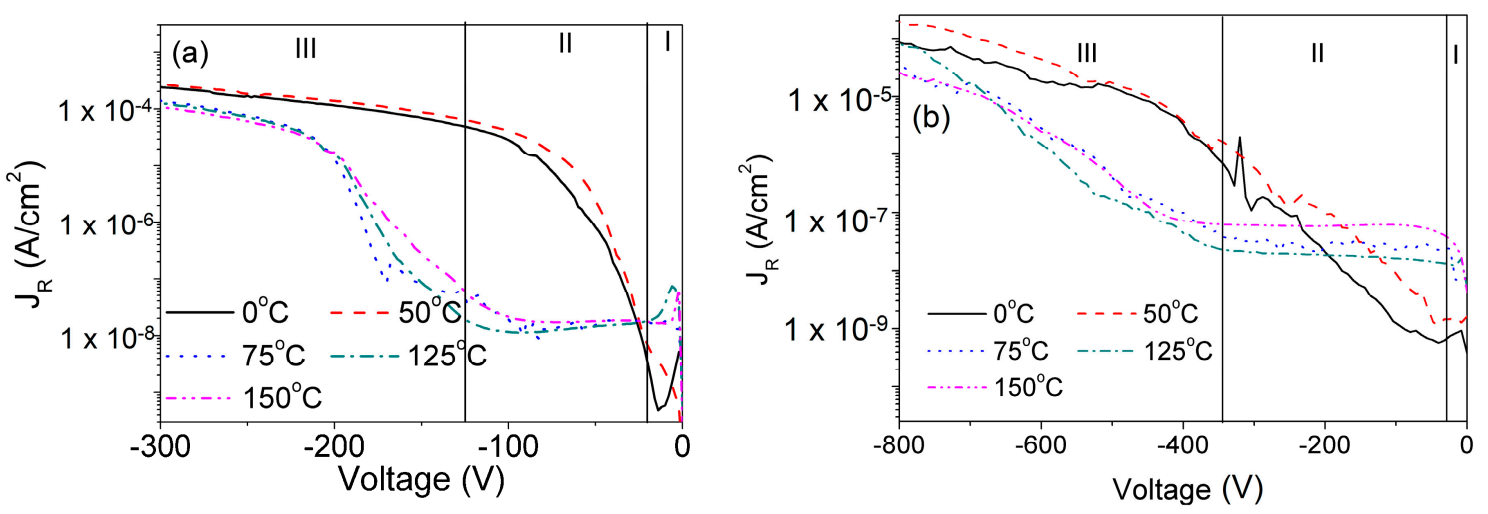

Figure 12. I-V-T characteristics of vertical GaN SBDs with (a) $15 \mu \mathrm{m}$ DL, (b) $30 \mu \mathrm{m}$ DL. Adapted from [58] A. Sandupatla et al. 2020 Appl. Phys. Express in press https://doi.org/10.35848/1882-0786/ab93a0. Copyright [2020] by Japanese Society of Applied Physics. 
Various changes in $\mathrm{CM}$ were observed with a change in both temperature and voltage, which have been shown in Figure 13. To understand the physical significance of the change in CM The activation energy was also extracted in all voltage zones $[55,56]$. The extracted $\mathrm{E}_{\mathrm{a}}$ of $0.4 \mathrm{eV}$ corresponds to the presence of $\mathrm{Mg}$ ions in the DL $[59,60]$. The activation of $\mathrm{N}$-vacancies [61] $\left(E_{a}=-1.67 \mathrm{eV}\right)$ with an increase in temperature resulted in the trapping of tunneling electrons and changing the CM from TFE to TE in Zone-II of both SBDs. Similarly, activation of C-traps $\left(E_{a}=0.69 \mathrm{eV}\right)$ released electrons into the depletion region when a high reverse voltage was supplied. The release of these electrons increased the probability of tunneling through the DW changing the CM to TFE. This change of CM at elevated temperatures can be used in aid of the design of high breakdown voltage SBDs for high-power switching and high-energy radiation sensing applications.
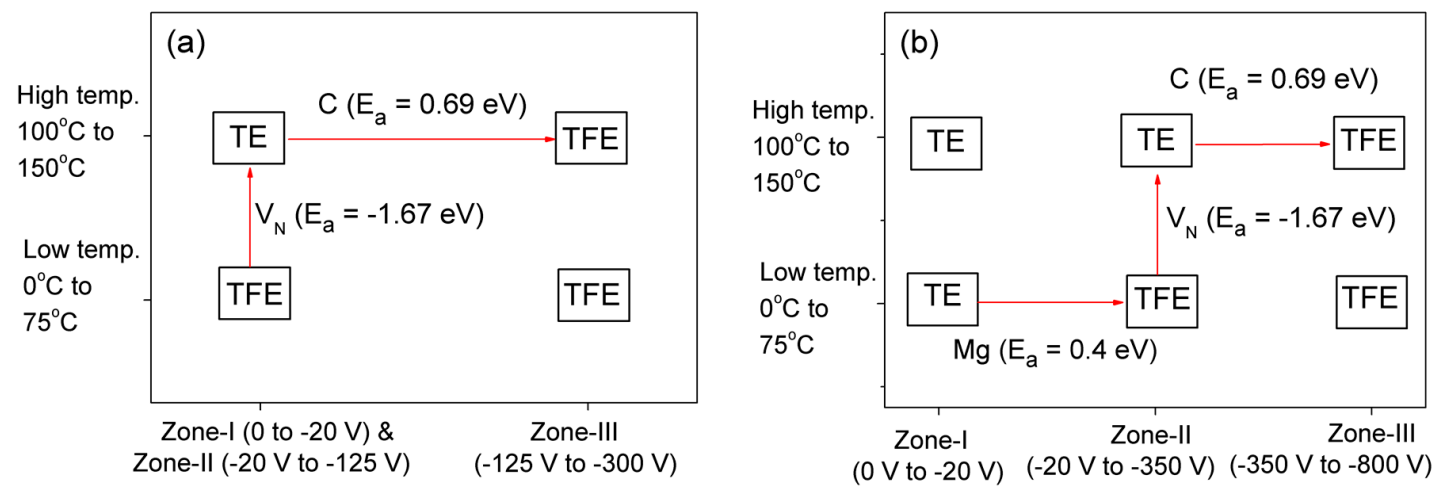

Figure 13. Change of CM with voltage zones and temperature ranges in SBDs with (a) $15 \mu \mathrm{m}$ DL and (b) $30 \mu \mathrm{m}$ DL. Adapted from [58] A. Sandupatla et al. 2020 Appl. Phys. Exp. https://doi.org/10.35848/ 1882-0786/ab93a0. Copyright [2020] by Japanese Society of Applied Physics.

\subsection{Breakdown Voltage of SBD}

The maximum voltage and power handling capability of SBDs are determined by its breakdown voltage characteristics. High voltages are essential to generate thick DW which is a primary requirement for an improved radiation detector performance. GaN has a high bandgap and high electric field strength, which makes it an optimum material to fabricate devices with high $\mathrm{V}_{\mathrm{BD}}$. For breakdown characterization, SBDs were exposed to increasing voltages until it reaches the set compliance of $1 \mathrm{~A} / \mathrm{cm}^{2}$ or when it reaches the catastrophic failure of the device. The SBDs were also dipped in Flourinert FC-40 prior to the measurements to insulate the SBDs from atmospheric flashover [62]. Figure 14 shows the semi-log breakdown characteristics of fabricated vertical SBDs with both $15 \mu \mathrm{m}$ and $30 \mu \mathrm{m}$ DLs. Thicker DW in SBDs with $30 \mu \mathrm{m}$ DLs results in larger $\mathrm{V}_{\mathrm{BD}}$.

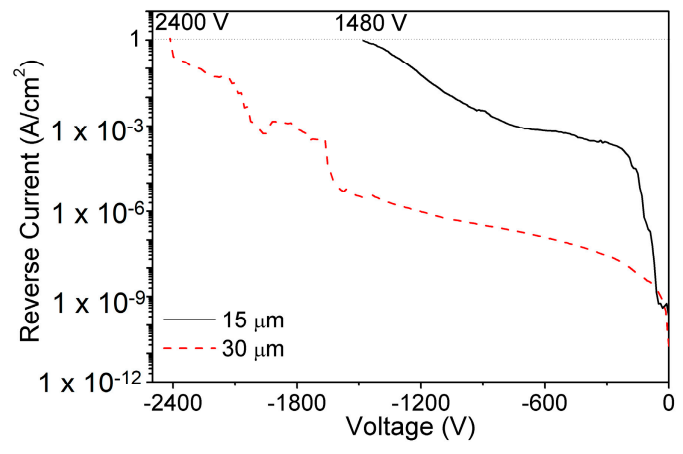

(a)

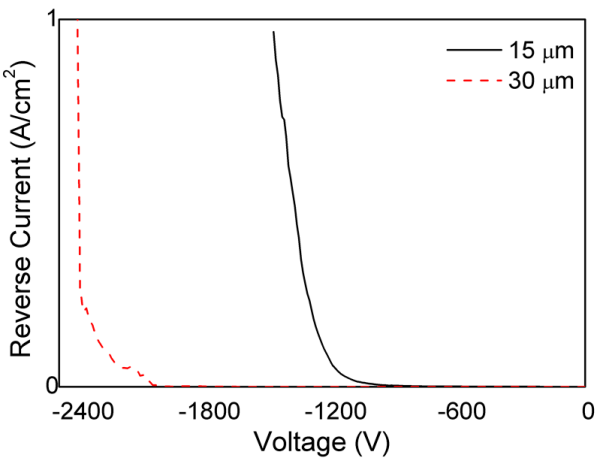

(b)

Figure 14. Reverse breakdown voltage characteristics of SBDs with $15 \mu \mathrm{m}$ and $30 \mu \mathrm{m}$ in (a) $\log$ and (b) linear scale. 
Figure 15 shows the plot of $\mathrm{V}_{\mathrm{BD}}$ vs. DLT for the state-of-the-art reported vertical SBDs [63-68]. Saitoh et al. realized a $\mathrm{V}_{\mathrm{BD}}$ of $1100 \mathrm{~V}$ for the SBDs with DLT of $5 \mu \mathrm{m}$ after using a field plate (FP) [63]. Shibata, D. et al. has reported the use of junction barrier Schottky (JBS) with p-type termination on SBDs with $13 \mu \mathrm{m}$ thick DL to measure a $\mathrm{V}_{\mathrm{BD}}$ value of $1600 \mathrm{~V}$ [64]. The improvement in $\mathrm{V}_{\mathrm{BD}}$ was reported to be due to the reduction of CCD in the MOCVD grown GaN DLs [43,58].

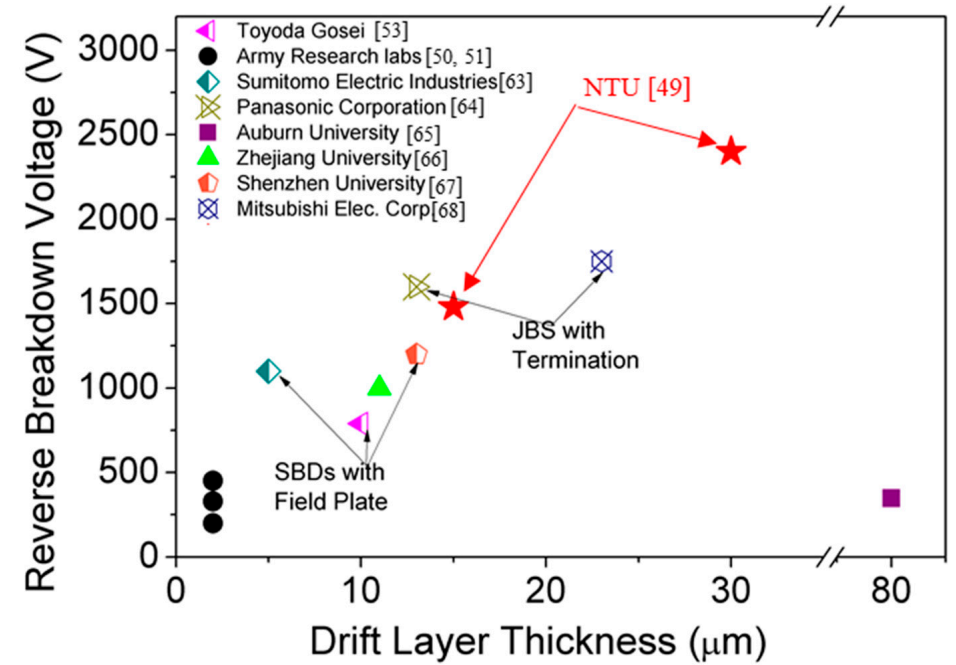

Figure 15. Benchmarking of measured reverse breakdown voltages of vertical GaN SBDs with state-of-the-art results.

\section{Measurement Setup for $\alpha$-Particle Detection}

After electrical characterization, both wafers were diced into individual detectors and packaged onto a dual inline package (DIP) with silver paste for the ground contact (cathode) and wire-bonding for the Schottky contact (anode) (see Figure 16a). $5.48 \mathrm{MeV} \alpha$-particles were generated from ${ }^{241} \mathrm{Am}$ source with an active area of $7 \mathrm{~mm}^{2}$, which was placed at $8 \mathrm{~mm}$ from the detector (as shown in Figure 16b). Radionuclides of ${ }^{241}$ Am were deposited onto a stainless-steel disc of $16 \mathrm{~mm}$ diameter, which was held in place by a plastic holder. The change in the current flowing through the circuit due to interaction with an $\alpha$-particle was amplified by passing through pre-amplifier, amplifier and signal processing circuit. A Si surface detector from ORTEC was used as a reference, along with an ORTEC-671 amplifier for energy calibration.

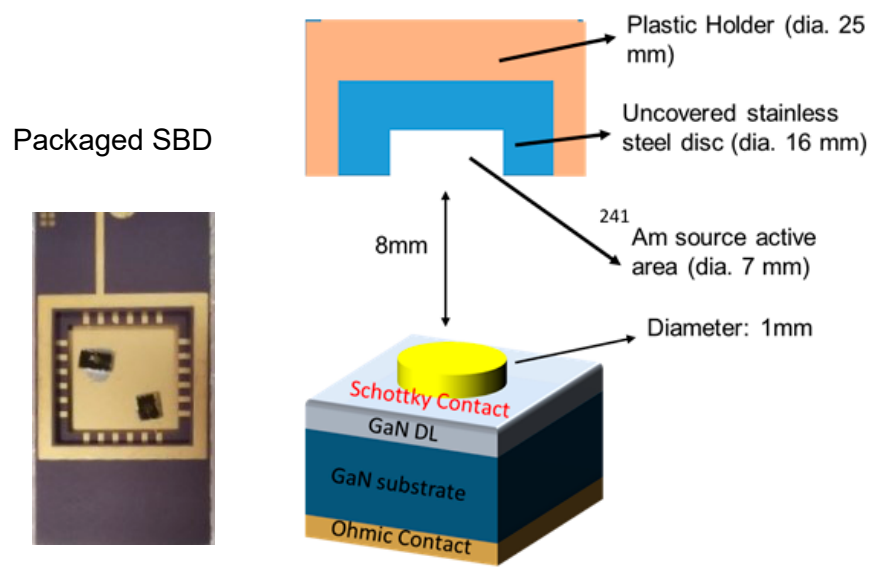

(a)

(b)

Figure 16. (a) Packaged Device and (b) Schematic drawing of Source-Detector measurement setup (not to scale). 


\subsection{Detection of $\alpha$-Particle Spectra}

The performance of any $\alpha$-particle detectors is defined by its CCE. CCE is defined as the ratio of energy detected and the energy incident on the detector. The acquired data needs to be calibrated using a standard Si detector as a reference [69,70]. The fabricated GaN detectors require higher energy for the generation of e-h pairs in comparison with the reference Si detectors. The final detected energy is described by the following Equation (4) [34]:

$$
E=E_{0}+W_{\mathrm{GaN}} / W_{\mathrm{Si}} \times k \times \text { Channel, }
$$

where $E$ is the energy absorbed, $E_{0}$ is the loss in energy at the metal-semiconductor interface, which can be estimated from Transport of Ions in Matter (TRIM) simulations; $k$ is a calibration factor of the reference detector; $W_{\mathrm{GaN}}$ is $8.9 \mathrm{eV}$ and $W_{\mathrm{Si}}$ is $3.6 \mathrm{eV}$.

\subsubsection{Low Voltage $\alpha$-Particle Detection}

For the detection of high energy $\alpha$-particles, researchers have increased the DW of the detectors by fabricating them on $\mathrm{GaN}$ substrates. These detectors have generated $27 \mu \mathrm{m}$ of the depleted region at very high voltages $(-550 \mathrm{~V})$ [34]. The requirement of high voltages in the generation of a thick DW increases the detector complexity and size, which severely affects its portability.

The $\alpha$-particle energy spectra obtained from the $15 \mu \mathrm{m}$ detectors under low-bias conditions ( -20 to $-80 \mathrm{~V}$ ) are shown in Figure 17a. Figure 17b compares the variation of CCE with the voltages of different reported detectors (sandwich structures). Detectors with compensated DL exhibited lower variation in CCE $(7 \%)$ in comparison to reports using a bulk GaN-based sandwich detector. The observation of lower variation in CCE was reported to be due to formation of a thick DW.

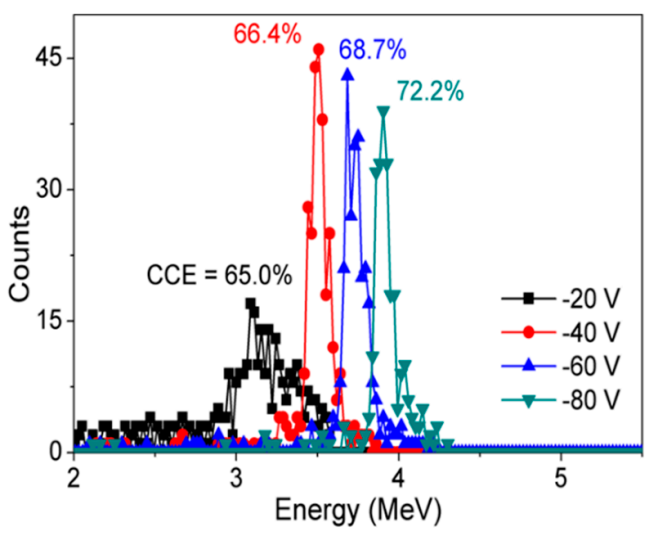

(a)

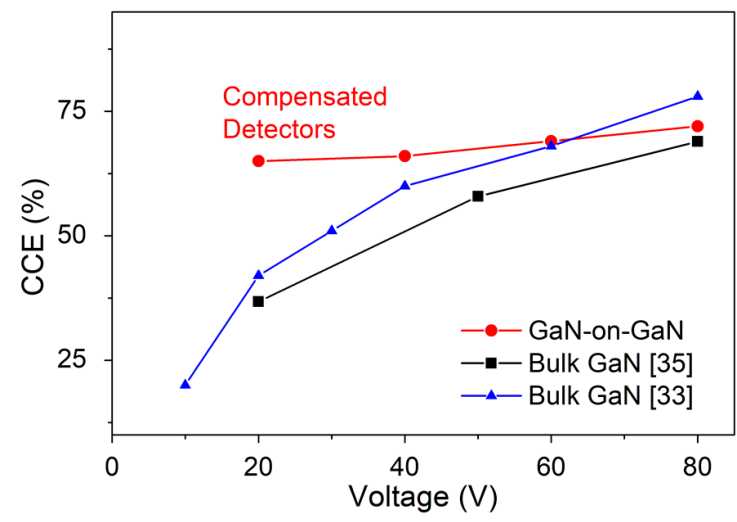

(b)

Figure 17. (a) Acquired $\alpha$-particle spectra of compensated detectors for different voltages ( $-20 \mathrm{~V}$ to $-80 \mathrm{~V})$ and (b) Comparison of variation in CCE with voltages $(-20 \mathrm{~V}$ to $-80 \mathrm{~V})$ for state-of-the-art $\alpha$-particle detectors.

\subsubsection{High Voltage $\alpha$-Particle Detection}

Although researchers have increased the energy detected by using bulk GaN-based sandwich structures, the complexity of generating a thick DW only two research groups have successfully developed $\alpha$-particle detectors capable of detecting $5.48 \mathrm{MeV}$ energy generated from ${ }^{241} \mathrm{Am}$ source. CCE of the compensated detectors improved from $72 \%$ at $-80 \mathrm{~V}$ to $96.7 \%$ at $-300 \mathrm{~V}$ (see Figure $18 \mathrm{a}$ ) due to the increase in DW. The high-voltage performance of the compensated detectors requires $250 \mathrm{~V}$ lower bias conditions in comparison to the detector fabricated by Q. Xu et al. (see Figure 18b). 


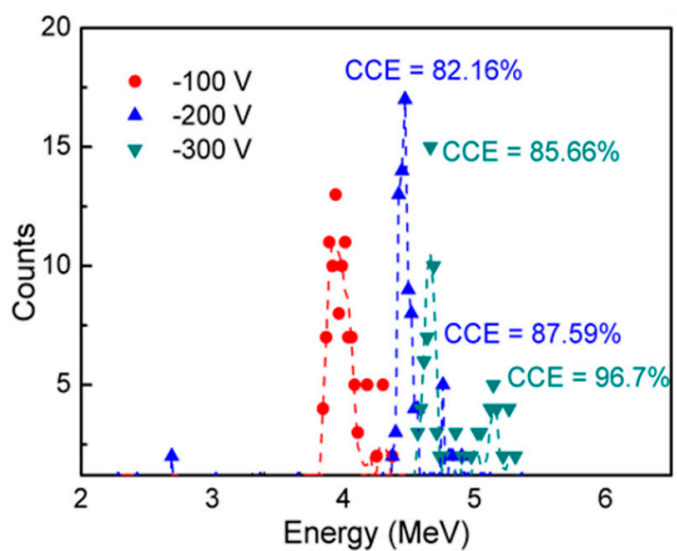

(a)

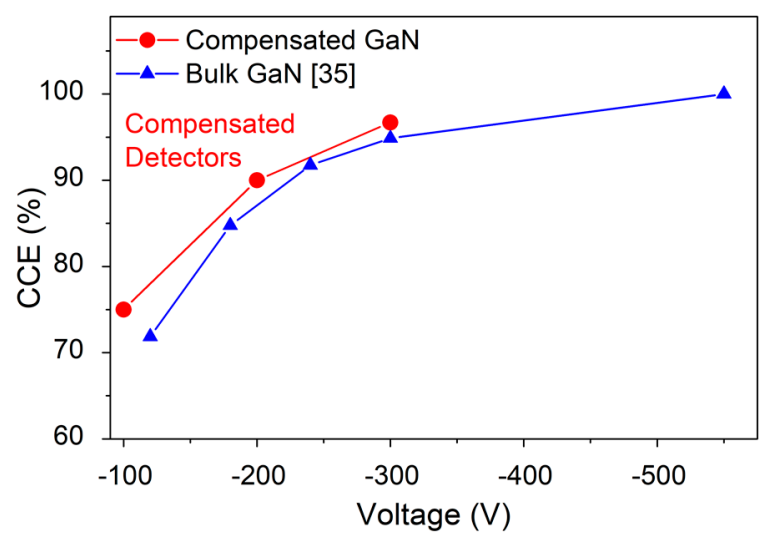

(b)

Figure 18. (a) $\alpha$-particle spectra of compensated GaN detectors for different applied voltages $(-100 \mathrm{~V}$ to $-300 \mathrm{~V})$ and $(\mathbf{b})$ Comparison of variation in CCE with voltages $(-100 \mathrm{~V}$ to $-550 \mathrm{~V})$ for state-of-the-art $\alpha$-particle detectors.

Figure 19 shows the $\alpha$-particle energy spectra obtained by SBD detectors with $30 \mu \mathrm{m}$ DL at different voltages $(-400 \mathrm{~V}$ to $-750 \mathrm{~V})$. An increase in applied bias conditions increases the detected energy increasing CCE. CCE of $100 \%$ in the detection of $5.48 \mathrm{MeV} \alpha$-particle was obtained at $-750 \mathrm{~V}$. The high CCE obtained ensures complete energy detection from incident charged $\alpha$-particle.

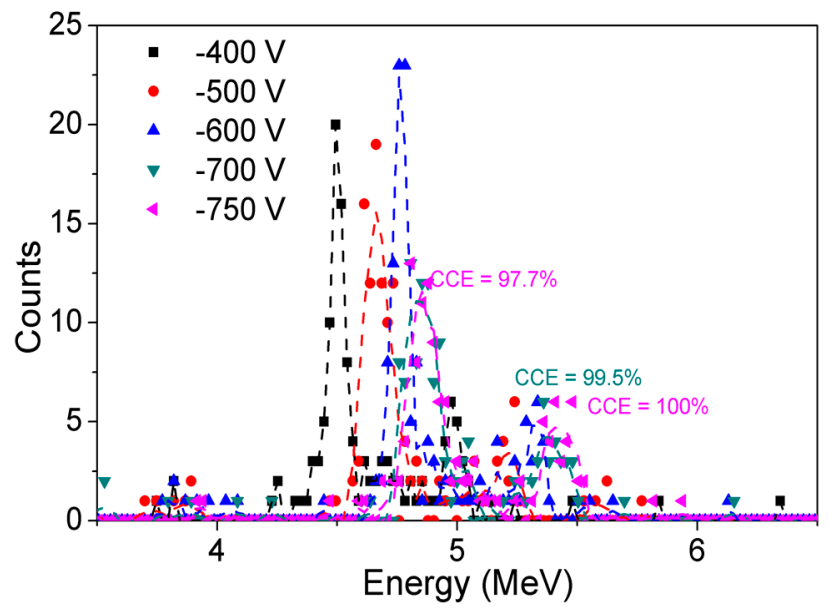

Figure 19. Acquired $\alpha$-particle energy spectra of GaN SBDs at different voltages in vacuum.

6.1.3. Variation in $\alpha$-Particle Spectra-Air vs. Vacuum (SBDs with $15 \mu \mathrm{m}$ DL)

Figure 20 shows the comparison of the energy spectrum of GaN detectors biased at $-100 \mathrm{~V}$ measured in a vacuum and in air reported for compensated detectors. $7 \%$ reduction in CCE was reported due to the presence of air. In vacuum, the complete energy of an $\alpha$-particle is transferred to the detector, resulting in the detection of higher energies. While in air energy of $\alpha$-particles is lost due to scattering. This loss in $\alpha$-particle energy lowers detected CCE. 


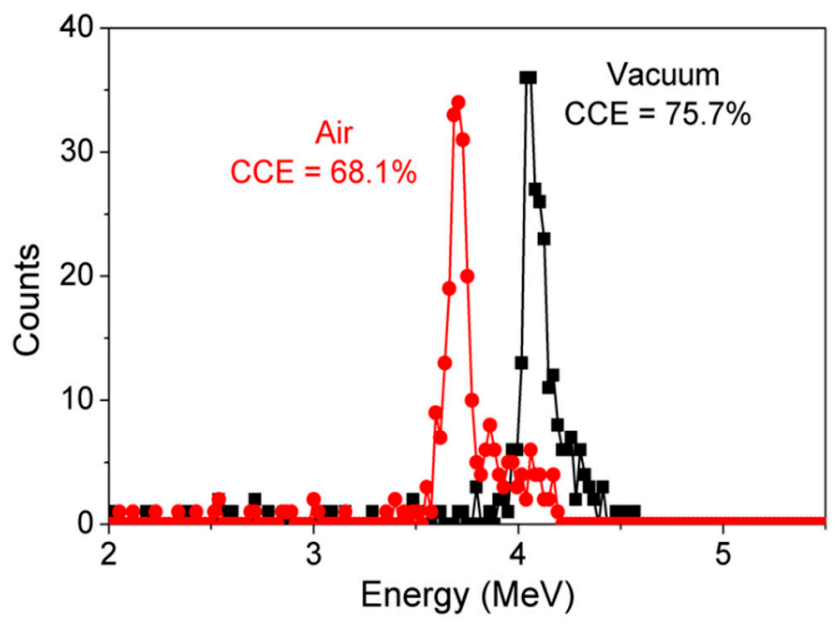

Figure 20. Acquired $\alpha$-particle energy spectra of GaN SBDs at $-100 \mathrm{~V}$ under air and in a vacuum.

\subsection{Benchmarking}

Figure 21 compares the performance of various reported GaN-based $\alpha$-particle detectors as a function of detected energies. About 30\% higher CCE was reported for the compensated $15 \mu \mathrm{m}$ $\alpha$-particle detectors at $-20 \mathrm{~V}$. In addition, compensated detectors also exhibit 96.7\% CCE at -300 V, which is $250 \mathrm{~V}$ in comparison to other published literature. These promising results pave the way for compensated $\alpha$-particle detectors to achieve high CCE with low operating voltage.

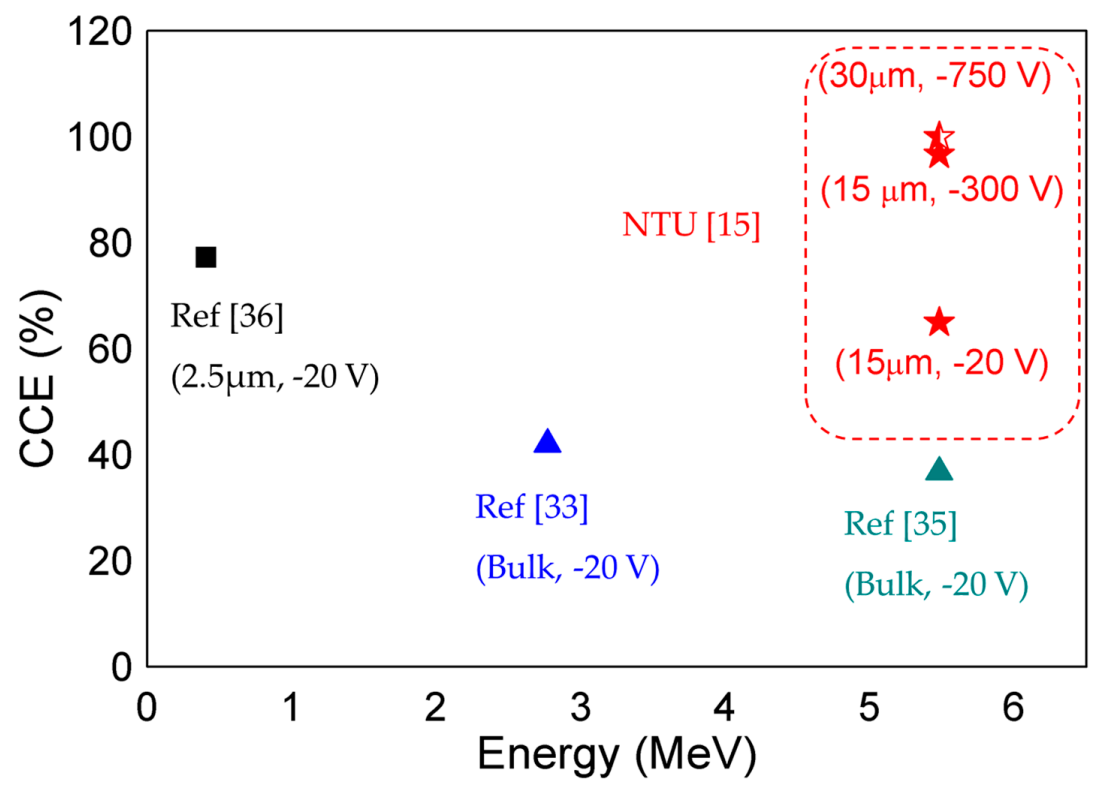

Figure 21. Benchmarking of extracted CCE of compensated detectors with epitaxial-grown GaN detectors (squares) and bulk GaN detectors (triangles) at low voltages.

\section{Summary}

GaN SBDs have demonstrated great potential in radiation detection on the virtue of its high displacement energy, wide bandgap and critical electric field strength. Conventionally, GaN particle detectors employ either a thin GaN epitaxial layer on the hetero-epitaxial substrate or thick free-standing GaN substrate to fabricate a radiation detector. While the thin epi-layer detector worked at low voltages $(-28 \mathrm{~V})$ with high CCE, they are only able to detect very low energies $(<1 \mathrm{MeV})$. The defects present in GaN such as high TDD and unintentional doping, have been the major constraints in terms of improving the detector performance. With improvement in growth technologies, free-standing GaN 
detectors with low TDD and doping densities have been fabricated which has increased the detected energy $(5.48 \mathrm{MeV})$ but they require very high voltages $(-550 \mathrm{~V})$ to detect these energies with $100 \%$ CCE.

High performing $\mathrm{GaN} \alpha$-particle detector can be achieved by designing a thin compensated $\mathrm{GaN}$ DL on conducting GaN substrate. Compensation of thin DL by doping p-type (Mg) ions in DL reduces the CCD generated by unintentional n-type doping. The increase in DW can reduce the $J_{R}$ and increased the $\mathrm{V}_{\mathrm{BD}}$ without affecting the ideality factor and barrier height of the SBDs. $\mathrm{A} \sim 3$ times improvement in $\mathrm{V}_{\mathrm{BD}}$ from $430 \mathrm{~V}$ to $1480 \mathrm{~V}$ due to compensation has helped realize SBDs with the highest reported $\mathrm{V}_{\mathrm{BD}}$ at $2400 \mathrm{~V}$ (SBDs with $30 \mu \mathrm{m}$ DL) without any additional termination or field plates.

The improvement in reverse characteristics have helped in improvement of the performance of the detector by improving the sensitivity and reducing the voltage requirement of the detector. These compensated GaN-on-GaN SBDs exhibit a 30\% increase in CCE (65\%) at low voltages (-20 V) in comparison to previously reported GaN $\alpha$-particle detectors. High CCE of $96.7 \%$ was also measured at $-300 \mathrm{~V}$, which is $250 \mathrm{~V}$ lower than the previously reported bias requirement. The improved performance in $\alpha$-particle detection is due to the formation of thicker DW at low voltages. The spectral resolution of $71 \mathrm{keV}$ is also $30 \%$ better than the previous reports. Presence of air results in scattering of $\alpha$-particle incident on the detector, which in turn reduced its efficiency by $\sim 7 \%$. While detectors with thicker DW do require a higher voltage $(750 \mathrm{~V})$ to detect $\alpha$-particles with $100 \% \mathrm{CCE}$, they can also detect higher energies $(9.1 \mathrm{MeV})$.

Author Contributions: A.S. along with S.A. and N.G.I. have designed the experiments; Simulations and fabrication of devices was completed by A.S.; Result analysis was completed by A.S., S.A. and N.G.I.; J.K. performed radiation detection testing and analysis.; S.N. and H.A. have grown the GaN material for fabrication of devices; A.S. wrote the paper, which was reviewed by all authors. All authors have read and agreed to the published version of the manuscript.

Funding: This research received no external funding

Conflicts of Interest: The authors declare no conflict of interest.

\section{References}

1. Lamarsh, J.R.; Baratta, A.J. Introduction to Nuclear Engineering; Prentice-Hall: Upper Saddle River, NJ, USA, 2001.

2. Stacey, W.M. Nuclear Reactor Physics; John Wiley \& Sons: Hoboken, NJ, USA, 2001.

3. Connor, N. What-Is-Detection-of-Alpha-Radiation-Alpha-Particle-Detector-Definition. Available online: https:/www.radiation-dosimetry.org/what-is-detection-of-alpha-radiation-alpha-particle-detector-definition/ (accessed on 14 December 2019).

4. Burn, R.R. Introduction to Nuclear Reactor Operation; Detroit-Edison: Detroit, MI, USA, 1988.

5. Rossi, B.; Staub, A.H.H. Ionization Chambers and Counters; McGraw-Hill Book Company Inc: New York, NY, USA, 1949.

6. Teo, W.R. Techniques for Nuclear and Particle Physics Experiments; Springer: Berlin/Heidelberg, Germany, 1993.

7. Knoll, G. Radiation Detection and Measurement; John Wiley and Sons Inc.: Ann Arbor, MI, USA, 2010.

8. Ionascut-Nedelcescu, A.; Carlone, C.; Houdayer, A.; Bardeleben, H.J.V.; Cantin, J.L.; Raymond, A.S. Radiation hardness of gallium nitride. IEEE Trans. Nucl. Sci. 2002, 49, 2733-2738. [CrossRef]

9. Devanathan, R.; Weber, W. Displacement energy surface in 3C and 6H SiC. J. Nucl. Mater. 2000, 278, $258-265$. [CrossRef]

10. Nord, J.; Nordlund, K.; Keinonen, J. Molecular dynamics study of damage accumulation in GaN during ion beam irradiation. Phys. Rev. B 2003, 68, 184104. [CrossRef]

11. Bourgoin, J.C.; Massarani, B. Threshold energy for atomic displacement in diamond. Phys. Rev. B 1976, 14, 3690. [CrossRef]

12. Ören, Ü.; Nilsson, J.; Herrnsdorf, L.; Rääf, C.L.; Mattsson, S. Silicon Diode as an Alpha Particle Detector and Spectrometer for Direct Field Measurements. Radiat. Prot. Dosim. 2016, 170, 247-251. [CrossRef]

13. Kang, S.M.; Ha, J.H.; Park, S.-H.; Kim, H.S.; Lee, N.H.; Kim, Y.K. Radiation Response of a Semi-insulating GaAs Semiconductor Detector for Charged Particle at Variable Operating Temperature. Prog. Nucl. Sci. Technol. 2011, 1, 282-284. [CrossRef] 
14. Zatko, B.; Dubecky, F.; Sagatova, A.; Sedlačová, K.; Ryc, L. High resolution alpha particle detectors based on 4H-SiC epitaxial layer. J. Instrum. 2015, 10, C04009. [CrossRef]

15. Sandupatla, A.; Arulkumaran, S.; Ranjan, K.; Ng, G.I.; Murmu, P.P.; Kennedy, J.; Nitta, S.; Honda, Y.; Deki, M.; Amano, H.; et al. Low Voltage High-Energy $\alpha$-Particle Detectors by GaN-on-GaN Schottky Diodes with Record-High Charge Collection Efficiency. Sensors 2019, 19, 5107. [CrossRef]

16. Wang, L.; Lou, Y.; Su, Q.; Shi, W.; Xia, Y. CVD diamond alpha-particle detectors with different electrode geometry. Opt. Express 2005, 13, 8612-8617. [CrossRef]

17. Chmill, V. Radiation Tests of Semiconductor Detectors; Kungl Tekniska H“Ogskolan Fysiska Institutionen: Stockholm, Sweden, 2006.

18. Meneghini, M.; Trevisanello, L.; Meneghesso, G.; Zanoni, E. A Review on the Reliability of GaN-Based LEDs. IEEE Trans. Device Mater. Reliab. 2008, 8, 323-331. [CrossRef]

19. Nakamura, S.; Mukai, T.; Senoh, M. Candela-class high-brightness InGaN/AlGaN double-heterostructure blue-light-emitting diodes. Appl. Phys. Lett. 1994, 64, 1687-1689. [CrossRef]

20. Trivellin, N.; Meneghini, M.; Zanoni, E.; Orita, K.; Yuri, M.; Meneghesso, G. A review on the reliability of GaN-based laser diodes. In Proceedings of the 2010 IEEE International Reliability Physics Symposium (IRPS), Anaheim, CA, USA, 2-6 May 2010.

21. Del Alamo, J.; Joh, J.; Del Alamo, J.A. GaN HEMT reliability. Microelectron. Reliab. 2009, 49, 1200-1206. [CrossRef]

22. Ranjan, K.; Arulkumaran, S.; Ing, N.G.; Sandupatla, A. Investigation of Self-Heating Effect on DC and RF Performances in AlGaN/GaN HEMTs on CVD-Diamond. IEEE J. Electron Devices Soc. 2019, 7, 1264-1269. [CrossRef]

23. Sun, X.; Li, D.; Li, Z.; Song, H.; Jiang, H.; Chen, Y.; Miao, G.; Zhang, Z. High spectral response of self-driven GaN-based detectors by controlling the contact barrier height. Nat. Sci. Rep. 2015, 5, 16819. [CrossRef]

24. Alifragis, Y.; Roussos, G.; Pantazis, A.K.; Konstantinidis, G.; Chaniotakis, N. Free-standing gallium nitride membrane-based sensor for the impedimetric detection of alcohols. J. Appl. Phys. 2016, 119, 74502. [CrossRef]

25. Nord, J.; Nordlund, K.; Keinonen, J.; Albe, K. Molecular dynamics study of defect formation in GaN cascades. Nucl. Instrum. Methods Phys. Res. Sect. B Beam Interact. Mater. At. 2003, 202, 93-99. [CrossRef]

26. Porowski, S.; Sadovyi, B.; Gierlotka, S.; Rzoska, S.J.; Grzegory, I.; Petrusha, I.; Turkevich, V.; Stratiichuk, D. The challenge of decomposition and melting of gallium nitride under high pressure and high temperature. J. Phys. Chem. Solids 2015, 85, 138-143. [CrossRef]

27. Sellin, P.; Vaitkus, J. New materials for radiation hard semiconductor dectectors. Nucl. Instrum. Methods Phys. Res. Sect. A Accel. Spectrometers Detect. Assoc. Equip. 2006, 557, 479-489. [CrossRef]

28. Weaver, B.D.; Anderson, T.J.; Koehler, A.D.; Greenlee, J.D.; Hite, J.K.; Shahin, D.I.; Kub, F.J.; Hobart, K.D. On the Radiation Tolerance of AlGaN/GaN HEMTs. ECS J. Solid State Sci. Tech. 2016, 5, Q208-Q212. [CrossRef]

29. Zhao, P.; Verma, A.; Verma, J.; Jena, D. Comparison of Schottky Diodes on Bulk GaN Substrates E GaN-on-Sapphire; CS Mantech: New Orleans, LA, USA, 2013.

30. Sugiura, M.; Kushimoto, M.; Mitsunari, T.; Yamashita, K.; Honda, Y.; Amano, H.; Inoue, Y.; Mimura, H.; Aoki, T.; Nakano, T. Study of radiation detection properties of GaN pn diode. Jpn. J. Appl. Phys. 2016, 55, 05FJ02. [CrossRef]

31. Wang, G.; Fu, K.; Yao, C.-S.; Su, D.; Zhang, G.-G.; Wang, J.-Y.; Lu, M. GaN-based PIN alpha particle detectors. Nucl. Instrum. Methods Phys. Res. Sect. A Accel. Spectrometers Detect. Assoc. Equip. 2012, 663, 10-13. [CrossRef]

32. Wang, J.; Mulligan, P.L.; Brillson, L.J.; Cao, L.R. Review of using gallium nitride for ionizing radiation detection. Appl. Phys. Rev. 2015, 2, 031102. [CrossRef]

33. Lee, I.H.; Polyakov, A.; Smirnov, N.B.; Govorkov, A.V.; Kozhukhova, E.A.; Zaletin, V.M.; Gazizov, I.M.; Kolin, N.G.; Pearton, S.J. Electrical properties and radiation detector performance of free-standing bulk n-GaN. J. Vac. Sci. Technol. B 2012, 30, 21205. [CrossRef]

34. Mulligan, P.L.; Wang, J.; Cao, L.R. Evaluation of freestanding GaN as an alpha and neutron detector. Nucl. Instrum. Methods Phys. Res. Sect. A Accel. Spectrometers Detect. Assoc. Equip. 2013, 719, 13-16. [CrossRef]

35. Xu, Q.; Mulligan, P.L.; Wang, J.; Chuirazzi, W.; Cao, L. Bulk GaN alpha-particle detector with large depletion region and improved energy resolution. Nucl. Instrum. Methods Phys. Res. Sect. A Accel. Spectrometers Detect. Assoc. Equip. 2017, 849, 11-15. [CrossRef] 
36. Vaitkus, J.V.; Cunningham, W.; Gaubas, E.; Rahman, M.; Sakai, S.; Smith, K.; Wang, T. Semi-insulating GaN and its evaluation for $\alpha$ particle detection. Nucl. Instrum. Methods Phys. Res. Sect. A Accel. Spectrometers Detect. Assoc. Equip. 2003, 509, 60-64. [CrossRef]

37. Min, L.; Guo-Guang, Z.; Kai, F.; Guo-Hao, Y. Gallium Nitride Room Temperature $\alpha$ Particle Detectors. Chin. Phys. Lett. 2010, 27, 052901. [CrossRef]

38. Polyakov, A.; Smirnov, N.B.; Govorkov, A.V.; Markov, A.V.; Kozhukhova, E.A.; Gazizov, I.M.; Kolin, N.G.; Merkurisov, D.I.; Boiko, V.M.; Korulin, A.V.; et al. Alpha particle detection with GaN Schottky diodes. J. Appl. Phys. 2009, 106, 103708. [CrossRef]

39. Ziegler, J.F.; Ziegler, M.; Biersack, J. SRIM-The stopping and range of ions in matter (2010). Nucl. Instrum. Methods Phys. Res. Sect. B Beam Interact. Mater. At. 2010, 268, 1818-1823. [CrossRef]

40. Shinoda, H.; Mutsukura, N. Structural properties of $\mathrm{GaN}$ layers grown on $\mathrm{Al}_{2} \mathrm{O}_{3}(0001)$ and $\mathrm{GaN} / \mathrm{Al}_{2} \mathrm{O}_{3}$ template by reactive radio-frequency magnetron sputter epitaxy. Vacuum 2016, 125, 133-140. [CrossRef]

41. Tanikawa, T.; Ohnishi, K.; Kanoh, M.; Mukai, T.; Matsuoka, T. Three-dimensional imaging of threading dislocations in GaN crystals using two-photon excitation photoluminescence. Appl. Phys. Express 2018, 11, 031004. [CrossRef]

42. Sandupatla, A.; Subramaniam, A.; Ng, G.I.; Ranjan, K.; Deki, M.; Nitta, S.; Honda, Y.; Amano, H. Enhanced breakdown voltage in vertical Schottky diodes on compensated GaN drift layer grown on free standing GaN. In Proceedings of the 13th International Conference of Nitride Semiconductors (ICNS-13), Bellevue, DC, USA, 7-12 July 2019.

43. Sandupatla, A.; Subramaniam, A.; Ng, G.I.; Ranjan, K.; Deki, M.; Nitta, S.; Honda, Y.; Amano, H. Improved breakdown voltage in vertical GaN Schottky barrier diodes on free-standing GaN with Mg-compensated drift layer. Jpn. J. Appl. Phys. 2019, 59, 010906. [CrossRef]

44. Hwang, Y.-H.; Ahn, S.; Dong, C.; Zhu, W.; Kim, B.-J.; Ren, F.; Lind, A.G.; Jones, K.S.; Pearton, S.J.; Kravchenko, I. Effect of Buffer Oxide Etchant (BOE) on Ti/Al/Ni/Au Ohmic Contacts for AlGaN/GaN Based HEMT. ECS Meet. Abstr. 2015, 69, 111-118. [CrossRef]

45. Wang, L.; Mohammed, F.M.; Adesida, I. Differences in the reaction kinetics and contact formation mechanisms of annealed Ti/Al/Mo/Au Ohmic contacts on n-GaN and AlGaN/GaN epilayers. J. Appl. Phys. 2007, 101, 13702. [CrossRef]

46. Feng, Q.; Li, M.; Hao, Y.; Ni, Y.; Zhang, C. The improvement of ohmic contact of Ti/Al/Ni/Au to AlGaN/GaN HEMT by multi step annealing method. Solid State Electron. 2009, 53, 955-958. [CrossRef]

47. Yang, L. Planar and Non Gold Metal Stacks Processes and Conduction Mechanism of AlGaN/GaN HEMTs on Si; Nanyang Technological University: Singapore, 2016.

48. Huang, Y.; Huang, Z.; Zhong, Z.; Yang, X.; Hong, Q.; Wang, H.; Huang, S.; Gao, N.; Chen, X.; Cai, D.; et al. Highly transparent light emitting diodes on graphene encapsulated $\mathrm{Cu}$ nanowires network. Sci. Rep. 2018, 8, 13721. [CrossRef] [PubMed]

49. Sandupatla, A.; Arulkumaran, S.; Ng, G.I.; Ranjan, K.; Deki, M.; Nitta, S.; Honda, Y.; Amano, H. GaN drift-layer thickness effects in vertical Schottky barrier diodes on free-standing HVPE GaN substrates. AIP Adv. 2019, 9, 045007. [CrossRef]

50. Tompkins, R.P.; Khan, M.R.; Green, R.; Jones, K.A.; Leach, J.H. IVT measurements of GaN power Schottky diodes with drift layers grown by HVPE on HVPE GaN substrates. J. Mater. Sci. Mater. Electron. 2016, 27, 6108-6114. [CrossRef]

51. Tompkins, R.P.; Smith, J.R.; Kirchner, K.W.; Jones, K.A.; Leach, J.H.; Udwary, K.; Preble, E.; Suvarna, P.; Leathersich, J.; Shahedipour-Sandvik, F. GaN Power Schottky Diodes with Drift Layers Grown on Four Substrates. J. Electron. Mater. 2014, 43, 850-856. [CrossRef]

52. Yamada, H.; Chonan, H.; Takahashi, T.; Shimizu, M. Electrical properties of Ni/n-GaN Schottky diodes on freestanding m-plane GaN substrates. Appl. Phys. Express 2017, 10, 41001. [CrossRef]

53. Tanaka, N.; Hasegawa, K.; Yasunishi, K.; Murakami, N.; Oka, T. 50 A vertical GaN Schottky barrier diode on a free-standing GaN substrate with blocking voltage of 790 V. Appl. Phys. Express 2015, 8, 71001. [CrossRef]

54. Tanaka, T.; Kaneda, N.; Mishima, T.; Kihara, Y.; Aoki, T.; Shiojima, K. Roles of lightly doped carbon in the drift layers of vertical n-GaN Schottky diode structures on freestanding GaN substrates. Jpn. J. Appl. Phys. 2015, 54, 41002. [CrossRef] 
55. Grant, J.; Bates, R.; Cunningham, W.; Blue, A.; Melone, J.; McEwan, F.; Vaitkus, J.; Gaubas, E.; O'Shea, V. GaN as a radiation hard particle detector. Nucl. Instrum. Methods Phys. Res. Sect. A Accel. Spectrometers Detect. Assoc. Equip. 2007, 576, 60-65. [CrossRef]

56. Wang, J. Evaluation of $\mathrm{GaN}$ as a Radiation Detection Material; The Ohio State University: Columbus, $\mathrm{OH}$, USA, 2012.

57. Abhinay, S.; Arulkumaran, S.; Ng, G.; Ranjan, K.; Deki, M.; Nitta, S.; Honda, Y.; Amano, H. Effects of Drift Layer Thicknesses in Reverse Conduction Mechanism on Vertical GaN-on-GaN SBDs grown by MOCVD. In Proceedings of the Electron Devices Technology and Manufacturing Conference (EDTM), Singapore, 13-15 March 2019.

58. Sandupatla, A.; Subramaniam, A.; Ng, G.I.; Ranjan, K.; Deki, M.; Nitta, S.; Honda, Y.; Amano, H. Change of high-voltage conduction mechanism in vertical GaN-on-GaN Schottky diodes at elevated temperatures. Appl. Phys. Exp. 2020. [CrossRef]

59. Pearton, S.J. GaN and Related Materials II; Gordon Breach and Science Publication: Gainesville, Florida, 2000.

60. Ko, K.; Lee, K.; So, B.; Heo, C.; Lee, K.; Kwak, T.; Han, S.W.; Cha, H.Y.; Nam, O. Mg-compensation effect in $\mathrm{GaN}$ buffer layer for AlGaN/GaN high-electron-mobility transistors grown on $4 \mathrm{H}-\mathrm{SiC}$ substrate. Jpn. J. Appl. Phys. 2016, 56, 015502. [CrossRef]

61. Xie, Z.; Sui, Y.; Buckeridge, J.; Catlow, C.R.A.; Keal, T.W.; Sherwood, P.; Walsh, A.; Farrow, M.R.; Scanlon, D.O.; Woodley, S.M.; et al. Donor and acceptor characteristics of native point defects in GaN. arXiv 2018, arXiv:1803.06273. [CrossRef]

62. Arulkumaran, S.; Vicknesh, S.; Ing, N.G.; Selvaraj, S.L.; Egawa, T. Improved Power Device Figure-of-Merit $\left(4.0 \times 10^{8} \mathrm{~V}^{2} \Omega^{-1} \mathrm{~cm}^{-2}\right)$ in AlGaN/GaN High-Electron-Mobility Transistors on High-Resistivity 4-in. Si. Appl. Phys. Express 2011, 4, 084101. [CrossRef]

63. Saitoh, Y.; Sumiyoshi, K.; Okada, M.; Horii, T.; Miyazaki, T.; Shiomi, H.; Ueno, M.; Katayama, K.; Kiyama, M.; Nakamura, T. Extremely Low On-Resistance and High Breakdown Voltage Observed in Vertical GaN Schottky Barrier Diodes with High-Mobility Drift Layers on Low-Dislocation-Density GaN Substrates. Appl. Phys. Express 2010, 3, 081001. [CrossRef]

64. Shibata, D.; Kajitani, R.; Handa, H.; Shiozaki, N.; Ujita, S.; Ogawa, M.; Tanaka, K.; Tamura, S.; Hatsuda, T.; Ishida, M.; et al. Vertical GaN-based power devices on bulk GaN substrates for future power switching systems. In Proceedings of the SPIE OPTO, San Francisco, CA, USA, 11 April 2018.

65. Wang, Y.; Xu, H.; Alur, S.; Sharma, Y.; Tong, F.; Gartland, P.; Issacs-Smith, T.; Ahyi, C.; Williams, J.; Park, M.; et al. Electrical characteristics of the vertical GaN rectifiers fabricated on bulk GaN wafer. Phys. Status Solidi C 2011, 8, 2430-2432. [CrossRef]

66. Yang, S.; Han, S.; Li, R.; Sheng, K. $1 \mathrm{kV} / 1.3 \mathrm{~m} \Omega \cdot \mathrm{cm}^{2}$ vertical GaN-on-GaN Schottky barrier diodes with high switching performance. In Proceedings of the International Symposium on Power Semiconductor Devices, Chicago, IL, USA, 13-17 May 2018.

67. Liu, X.; Liu, Q.; Li, C.; Wang, J.; Yu, W.; Xu, K.; Ao, J.-P. 1.2 kV GaN Schottky barrier diodes on free-standing GaN wafer using a CMOS-compatible contact material. Jpn. J. Appl. Phys. 2017, 56, 26501. [CrossRef]

68. Hayashida, T.; Nanjo, T.; Furukawa, A.; Watahiki, T.; Yamamuka, M. Leakage current reduction of vertical GaN junction barrier Schottky diodes using dual-anode process. Jpn. J. Appl. Phys. 2018, 57, 040302. [CrossRef]

69. Kennedy, J.V.; Markwitz, A.; Trodahl, H.J.; Ruck, B.J.; Durbin, S.M.; Gao, W. Ion beam analysis of amorphous and nanocrystalline group III-V nitride and ZnO thin films. J. Electron. Mater. 2007, 36, 472-482. [CrossRef]

70. Murmu, P.P.; Kennedy, J.V.; Ruck, B.J.; Rubanov, S. Micostructural, electrical and magnetic properties of erbium doped zinc oxide single crystals. Electron. Mater. Lett. 2015, 11, 998-1002. [CrossRef]

(C) 2020 by the authors. Licensee MDPI, Basel, Switzerland. This article is an open access article distributed under the terms and conditions of the Creative Commons Attribution (CC BY) license (http://creativecommons.org/licenses/by/4.0/). 